\title{
NOMBRES Y CLASIFICACIONES DE LOS HONGOS SEGÚN LOS CAMPESINOS de La Paz (Valle de Traslasierra, Córdoba, Argentina)
}

\author{
MARCO FLAMINI'1 GERARDO L. ROBLEDO ${ }^{1}$ y MARÍA E. SUÁREZ²
}

\begin{abstract}
Resumen: La etnomicología es una rama de la etnobiología dedicada a estudiar el papel de los hongos en las diversas culturas. El estudio de los nombres que un pueblo aplica a los elementos de su entorno es útil como punto de partida para dilucidar patrones nomenclaturales subyacentes y con ello aproximarse a la manera en que la gente los conceptualiza, percibe, valora y clasifica. En Argentina, y particularmente en Córdoba, son escasos y fragmentarios los datos disponibles sobre los vínculos y conocimientos que los diferentes grupos humanos poseen sobre los hongos. Para contribuir a cambiar esta situación, se realizó una investigación etnomicológica con los campesinos serranos del poblado de La Paz. Se trabajó con un enfoque cualitativo; los datos se recopilaron mediante entrevistas abiertas, recorridos por el entorno y observación participante. Se registraron 26 nombres locales para 31 especies fúngicas estudiadas; éstos se analizaron lingüísticamente. Se encontró que los criollos agrupan a dichas especies en 9 categorías nombradas en base a, principalmente, características morfológicas y al sustrato. A partir de los resultados se propone un primer esquema etnoclasificatorio de las especies, donde se observa que las categorías vernáculas en ocasiones se traslapan y no conforman un sistema absolutamente jerarquizado.
\end{abstract}

Palabras clave: Etnobiología, micología, etnomicología, conocimiento tradicional, etnotaxonomía, lingüística.

Summary: Names and classification of fungi according to the peasants from La Paz (Traslasierra valley, Córdoba, Argentina). Ethnomycology is considered a subfield of ethnobiology that studies the roles of fungi in different cultures. The study of the names that people give to the elements of their environment is a useful starting point for elucidating the underlying nomenclatural patterns, and for understanding the ways in which people conceptualize, perceive, value and classify them. In Argentina, and specifically in the province of Córdoba, the data available in the literature about the relationships and knowledge of fungi among different peoples are scarce and fragmentary. In order to contribute to modify this situation, a qualitative ethnomycological research was carried out among peasants of La Paz, which focused on the study of those topics. Data were collected through open interviews, walks through the area and participant observation. 26 local names were registered for the 31 fungal species that were studied. Names were linguistically analyzed, and results show that peasants group these species in nine categories, based mainly on morphological and substrate characteristics. Based on these results, an ethnoclassificatory scheme of the species is proposed, which shows that vernacular categories occasionally overlap and do not define an absolutely hierarchical system.

Key words: Ethnobiology, mycology, ethnomycology, traditional knowledge, ethnotaxonomy, linguistics.

\footnotetext{
${ }^{1}$ Laboratorio de Micología, Instituto Multidisciplinario de Biología Vegetal (IMBIV), CONICET, Universidad Nacional de Córdoba, flaminim@gmail.com,glrobledo@yahoo.com.

2 Departamento de Biodiversidad y Biología Experimental y PROPLAME-PRHIDEB (CONICET-UBA), Facultad de Ciencias Exactas y Naturales, Universidad de Buenos Aires, eugesuarez78@gmail.com.
} 


\section{INTRODUCCIÓN}

La etnomicología es una rama de la etnobiología, cuyo establecimiento se debe a los primeros trabajos de Valentina y Gordon Wasson a mediados del siglo pasado. En su momento, Wasson definió a la disciplina como "el estudio del rol de los hongos, en el sentido más amplio, en el pasado de la humanidad" (Wasson et al., 2008). Actualmente la etnomicología no se limita a estudiar el papel de los hongos en el pasado, sino que abarca también sus roles actuales. Así, la disciplina aborda la descripción y el análisis de los diferentes usos, creencias, percepciones y prácticas -tanto actuales como antiguos- de uno o más grupos humanos sobre los hongos de su entorno (Arora \& Shepard, 2008; Yamin-Pasternak, 2011).

Cada pueblo posee un vasto y particular conjunto de nombres y categorías que asignan a los elementos naturales de su entorno, fruto de una muy antigua historia de relaciones establecida a lo largo de generaciones y a la necesidad cognitiva de toda sociedad de ordenar y entender el mundo que la rodea (Lévi-Strauss, 1964). La lengua, además de servir para comunicarse, es un instrumento de conceptualización; y en ella suele haber rastros de muchos elementos, operaciones, procesos y categorías culturales (Fowler, 1979; Cardona, 1994; Duranti, 2000). Así, si bien no todo está codificado o explicitado en el sistema gramatical y en el léxico, un análisis lingüístico de la nomenclatura asociada a la naturaleza a nivel morfosintáctico y semántico permite comenzar a dilucidar patrones nomenclaturales subyacentes, y suele arrojar información valiosa sobre las clasificaciones vernáculas de los elementos del entorno y las formas particulares de la sociedad de percibirlos, concebirlos y valorarlos (cfr. Fowler, 1979; Mapes et al., 1981; Berlin, 1992; Ellen, 2000; Suárez, 2010, 2011, 2014; Scarpa 2012a).

Como ocurre en cualquier otra rama de la etnobiología, existen distintos enfoques y marcos epistemológicos en los que un estudio etnomicológico puede desarrollarse. Esta investigación es de índole cualitativa, fue realizada enteramente dentro del paradigma interpretativo de indagación, con una perspectiva etnográfica (González Monteagudo, 2000; Arenas \& Martínez, 2012; Wahyuni, 2012).

\section{Contexto ambiental y cultural}

La investigación se desarrolló en el valle de Traslasierra de la provincia de Córdoba, en los poblados de $\mathrm{La} \mathrm{Paz}\left(31^{\circ} 56^{\prime} 00^{\prime \prime} \mathrm{S} 65^{\circ} 12^{\prime} 00^{\prime \prime} \mathrm{O}\right)$ y Loma Bola $\left(32^{\circ} 13^{\prime} 08^{\prime \prime} \mathrm{S} 65^{\circ} 01^{\prime} 34^{\prime \prime} \mathrm{O}\right)$, y sus alrededores (Fig. 1), situados en el Departamento San Javier. Las principales actividades económicas de la zona son la producción de olivares y plantas aromáticas; además tiene una gran afluencia turística, principalmente en los meses de verano, por lo que muchas familias se dedican a la producción de artesanías y productos regionales para la venta al público (Buguña \& Cometta, 2010).

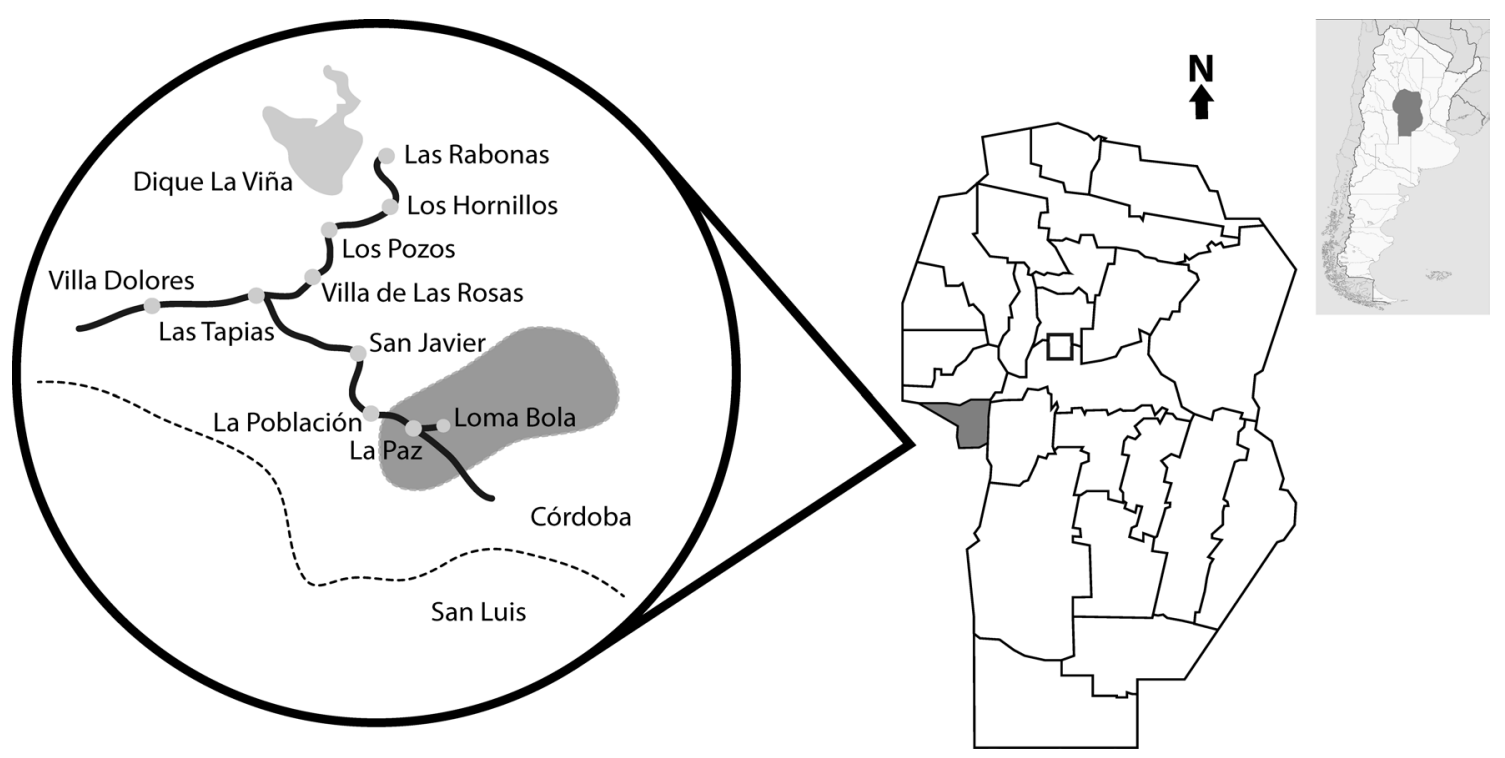

Fig. 1. Área de estudio. Traslasierra, Córdoba (Argentina). 


\section{Flamini et al. - Nombres y clasificaciones de los hongos de La Paz, Córdoba}

Desde el punto de vista fitogeográfico, el área de estudio se encuentra en el Distrito Chaqueño Serrano de la provincia Chaqueña, que se caracteriza por una vegetación dominada por bosques xerófilos de 'orco quebracho' (Schinopsis lorentzii (Griseb.) Engl.), 'molle' (Lithraea molleoides (Vell.) Engl.) y 'coco' (Zanthoxylum coco Gillies ex Hook. f. \& Arn.) (Cabrera, 1971; Luti et al., 1979). Sin embargo, desde hace varias décadas los bosques de las zonas serranas de la provincia de Córdoba vienen sufriendo grandes transformaciones en su estructura, fisonomía y distribución, causadas principalmente por el avance de las urbanizaciones, la deforestación, los incendios, la invasión de especies exóticas y el sobrepastoreo (Aragón \& Morales, 2003; Zak et al., 2004). Por esos motivos, el paisaje actual está representado por un mosaico de manchones de bosque de especies nativas o de especies nativas y exóticas, junto con fachinales y pastizales de sustitución (Zak et al., 2004). Además, en la zona existen extensas áreas forestadas con Pinus spp. que forman manchones de bosque monoespecíficos.

La información disponible sobre aspectos socioculturales de las poblaciones de campesinos serranos de Traslasierra es realmente escasa. Se presenta a continuación un panorama general de las características más destacables de la vida cotidiana de los serranos de La Paz y Loma Bola, que sirve para singularizar su situación, y se basa en un diagnóstico rural rápido de tipo exploratorio (Coirini \& Robledo, 1999) realizado a partir de los datos bibliográficos disponibles con otros obtenidos de primera mano.

El contexto cultural está conformado por habitantes de distintos orígenes, historias de vida y clases sociales. En esta investigación son los campesinos criollos que viven o han pasado parte de su vida en hogares dispersos en las laderas de las serranías, alejados del centro del pueblo e inmersos en el monte, quienes nos interesan. Todos ellos hablan español como lengua materna. Actualmente, la mayoría vive en casas hechas a partir de barro, rocas y troncos de árboles de la zona, con techo de paja y cañas, sin tendido eléctrico, gas natural ni agua corriente; otros están asentados en casas de material en los poblados de Loma Bola y La Paz. Habitualmente la vivienda está habitada por la familia extensa, de modo que no es raro encontrar, además de la familia nuclear, a abuelos y otros parientes cercanos como tíos y primos. Los terrenos y casas donde vivieron sus antepasados, hoy en día son en su mayoría propiedad de otras personas y se encuentran alambrados. En muchos casos, las familias fueron coaccionadas para "vender" sus propiedades, $\mathrm{y}$ en otros fueron directamente despojadas de las tierras en las que históricamente habitaron.

Muchos de los campesinos -sino la mayoría- son analfabetos. Las principales problemáticas sanitarias en la zona son el alcoholismo (especialmente entre los hombres) y el Mal de Chagas. En cuanto a los aspectos religiosos, son católicos y participan activamente de celebraciones o festividades religiosas como bautismos, comuniones, confirmaciones, celebración del vía crucis, etc.

La economía familiar depende de actividades laborales informales, discontinuas y de marcada fluctuación estacional: venta de bienes y servicios vinculados al turismo (venta de hierbas aromáticas, hongos silvestres y productos regionales, guías de cabalgatas, entre otros), changas y trabajos ocasionales como albañiles, trabajos en quintas y estancias con animales y cultivos, venta de leña, etc. Vale la pena destacar que la venta de hierbas silvestres alcanza a involucrar hasta un $80 \%$ de los habitantes de la zona y es en gran medida la base de su subsistencia (Lagrotteria \& Affolter, 1999). En el caso particular de las mujeres, ellas suelen trabajar como empleadas domésticas o en hoteles y alojamientos de la zona, donde realizan labores variadas, y además llevan a cabo una serie de actividades específicas vinculadas al arte textil, como hilados de lana de oveja, tinciones con anilinas, hongos y vegetales, y la confección de tejidos con distintas técnicas para venderlos además de usarlos la propia familia.

Por las particularidades de su forma de vida cotidiana, es evidente que este grupo de campesinos mantiene un contacto íntimo con su entorno natural y cuenta con una larga tradición en la recolección, uso y comercialización de hierbas y hongos silvestres. A pesar de que la mayoría se refiere a ellos mismos y a sus pares bajo la denominación de "yuyeros", a lo largo del trabajo se aludirá al grupo humano bajo estudio, indistintamente, como "campesinos", "criollos", "serranos", "yuyeros" o alguna combinación de dichas denominaciones, dado que todos ellos son términos habitualmente usados en la literatura y en la zona de estudio. 


\section{Antecedentes y relevancia de la investigación}

Actualmente, los hongos conforman un grupo de organismos independiente (Reino Fungi); sin embargo, hasta hace pocos años se los clasificaba dentro del reino vegetal e incluso hoy la micología mantiene una estrecha relación con la botánica. Esto generó que, en el ámbito de la etnobiología, los hongos sean usualmente tratados como un elemento vegetal más dentro de estudios etnobotánicos y que las investigaciones exclusivamente etnomicológicas sean relativamente escasas. En esta línea, con excepción de unos pocos trabajos (Keller, 2000, 2008), en la Argentina la mayor cantidad de información etnomicológica se encuentra dispersa en trabajos etnobotánicos realizados desde distintos enfoques y en diferentes regiones del país pero cuyo interés, en todos los casos, está centrado en las interrelaciones plantas-humanos y no en las de hongos-humanos (cfr. Martínez Crovetto, 1968; Arenas, 2003; Martínez, 2007, 2010; Filipov \& Arenas, 2008; Martínez \& Cúneo, 2009; Scarpa, 2009, 2012b, 2013; Domínguez Díaz, 2010; Hernández et al., 2010; Keller, 2010; Ochoa et al., 2010; Suárez \& Montani, 2010; Suárez \& Arenas, 2012; Suárez, 2014). Existen además ciertos datos aislados en trabajos abordados desde la micología, la biología o la ecología (v. g. Deschamps, 2002; Acosta, 2009; Niveiro et al., 2009; Robledo \& Urcelay, 2009; Fernández et al., 2012). Sin embargo, salvo contadas obras (Keller, 2000, 2008; Suárez \& Montani, 2010; Suárez, 2014), la mayoría de los estudios citados se limitan exclusivamente a la mención o descripción de usos prácticos y en ocasiones de nombres vernáculos de hongos, dejando de lado el examen pormenorizado de las percepciones, clasificaciones y otros tipos de vínculos entre éstos y las culturas.

Lo antedicho es particularmente válido para la provincia de Córdoba. Los trabajos que proveen información específica sobre el rol de los hongos en las poblaciones cordobesas son pocos, incluyen a los hongos como un elemento vegetal más, y por lo general los datos se reducen a mencionar o describir a los hongos útiles para los campesinos v. g. Phlebopus bruchii (Speg.) Heinem. \& Rammeloo, Suillus granulatus (L.) Roussel, Calvatia cyathiformis (Bosc) Morgan, Usnea spp., en particular en el ámbito alimenticio, medicinal, tintóreo o económico (Deschamps, 2002; Martínez \& Planchuelo, 2003; Martínez, 2005, 2008, 2010;
Arias Toledo et al., 2007; Trillo \& Demaio, 2007; Trillo et al., 2007; Arias Toledo, 2009; Trillo, 2010; Furlan et al., 2011; Madaleno \& Montero, 2012). De modo que la etnomicología en Córdoba y en el país resulta ser un campo prácticamente inexplorado.

Sin embargo, es consabido que los hongos, en especial los macrohongos (i. e. hongos con fructificaciones macroscópicas), revisten gran importancia en diferentes culturas del mundo: su relevancia práctica y simbólica se observa en un sinnúmero de expresiones y elementos del arte tradicional, de su cultura material, en su uso como medicinas o alimentos, o en ciertos aspectos de sus sistemas clasificatorios y de su miconimia (Schultes \& Hofmann, 2000; Boa, 2004; Arora \& Shepard, 2008; Yamin-Pasternak, 2011). Asimismo, los hongos macroscópicos conforman uno de los grupos más importantes entre los productos forestales no madereros (PFNM) a nivel mundial, y constituyen una significativa fuente de ingresos económicos y de alimento para numerosas familias que los recolectan, principalmente en países en desarrollo (Boa, 2004). Resulta entonces fundamental estudiar las particularidades de las relaciones recíprocas entre las poblaciones campesinas cordobesas y los hongos de su entorno, ya que su conocimiento y entendimiento pueden contribuir a la elaboración de proyectos de desarrollo local factibles, sustentables, de interés y que resulten en una mejora en la calidad de vida de la gente. A más de esto, en contextos como el de Córdoba donde el ambiente está siendo devastado y el conocimiento tradicional de los campesinos serranos se ve cada vez más concentrado en unas pocas personas, generalmente de edad avanzada, los estudios etnobiológicos en general son urgentes y juegan un papel fundamental en el "rescate" de saberes ancestrales (Ladio, 2001; Arias Toledo, 2006, 2009; Trillo et al., 2007; Trillo, 2010; Arenas \& Martínez, 2012).

En este escenario, el presente trabajo pretende contribuir al conocimiento de la etnomicología de la provincia de Córdoba, en particular a la de los habitantes de La Paz, Loma Bola y alrededores. Para ello, se plantean como objetivos:

- Detallar y examinar los nombres vernáculos aplicados a los hongos y evaluar sus significados y motivaciones.

- Identificar y analizar las categorías vernáculas en las que se agrupan a los hongos. 


\section{Flamini et al. - Nombres y clasificaciones de los hongos de La Paz, Córdoba}

- Dilucidar los patrones nomenclaturales subyacentes a la miconimia de los campesinos serranos.

- Proponer un modelo del sistema etnoclasificatorio que utilizan los campesinos serranos.

\section{Materiales y Métodos}

Acorde con el marco epistemológico en el que se ubica la investigación, la metodología aplicada a lo largo de la investigación es de índole cualitativa (Mello Amorozo \& Viertler, 2008; Silva et al., 2008; Arenas \& Martínez, 2012). Se trabajó mediante la metodología ya clásica en etnobiología y sus sub disciplinas, que involucra tanto trabajo de campo como trabajo de gabinete y laboratorio, y que integra técnicas de las ciencias sociales y las naturales (Martin, 1995; Yamin-Pasternak, 2011; Arenas \& Martínez, 2012).

Se realizaron tres viajes a la zona de estudio que se desarrollaron entre el 06 de enero y el 03 de febrero de 2012, entre el 23 de marzo y el 14 de abril de 2012, y entre el 15 de febrero y el 09 de marzo de 2013. Los trabajos de campo se concentraron en los meses de verano y principios del otoño, épocas de lluvia en la zona y por ende en las que resulta más probable encontrar fructificaciones fúngicas. Durante las campañas se entrevistó a un total de 14 personas (5 mujeres y 9 varones), de 46 a 99 años de edad, y con cada una de ellas se tuvo un mínimo de 3 y un máximo de 7 encuentros.

Antes de comenzar el trabajo, se obtuvo el consentimiento informado de manera oral de cada una de las personas consultadas, siguiendo las recomendaciones del código de ética de la Sociedad Internacional de Etnobiología (ISE, 2006). Para la selección de las personas entrevistadas se utilizó el método "bola de nieve" y en todos los casos se trabajó con personas calificadas o informantes clave (Martin, 1995; Bernard, 2000).

La información etnomicológica se recopiló a través de tres métodos: a) recorridos a pie por la zona en compañía de las personas entrevistadas, b) entrevistas orales abiertas y semiestructuradas, realizadas con el apoyo de una guía temática específica confeccionada con antelación en base a los objetivos del estudio, y c) observación participante (Taylor \& Bogdan, 1987; Martin, 1995; Bernard, 2000; Guber, 2001; Arenas \& Martínez,
2012). El material biológico de referencia se recolectó siempre en compañía de los entrevistados, durante las caminatas. Para la colección y conservación de las muestras fúngicas se siguieron los lineamientos descriptos por Robledo \& Urcelay (2009). Se recolectaron todas las especies que eran consideradas "hongos" por los entrevistados, así como otras consideradas como tales por la micología occidental, de modo de indagar sobre la clasificación vernácula de las mismas (Tabla 1). Se recolectaron también muestras vegetales, en particular de aquellas plantas que estaban vinculadas a los hongos, ya sea porque eran sustrato de algún hongo, o porque según los campesinos guardaban algún otro tipo de asociación biológica, $\mathrm{o}$ porque se las nombraba en algún proceso o actividad que involucraba hongos como recetas culinarias, medicinas, tinciones, entre otros; las plantas fueron recolectadas y herborizadas en el campo en pliegos de papel de diario siguiendo la metodología y lineamientos de Martin (1995). Todos los ejemplares fueron trasladados al laboratorio y conservados allí hasta su identificación. Los nombres científicos de los hongos y vegetales estudiados, siguieron las propuestas del "Index Fungorum" (http://www.indexfungorum.org) y del "Catálogo de las Plantas Vasculares del Conosur" (http://www2.darwin.edu.ar/Proyectos/ FloraArgentina/FA.asp) respectivamente. Una vez identificados, los materiales se depositaron en el Herbario del Museo Botánico (CORD) de la Universidad Nacional de Córdoba.

La metodología de análisis de datos consistió en un estudio pormenorizado y de interpretación conjunta y holística del contenido de las entrevistas realizadas, de los datos provenientes de la observación participante y de la información encontrada en la bibliografía consultada, en función de los objetivos planteados (González Monteagudo, 2000; Guber, 2001; Arenas \& Martínez, 2012; Wahyuni, 2012). Los análisis se realizaron considerando tanto la perspectiva del grupo humano bajo estudio (perspectiva émica), como el punto de vista de la ciencia académica (perspectiva ética) (Arenas \& Martínez, 2012). Los nombres vernáculos fueron examinados lingüísticamente a nivel morfosintáctico y semántico, tal como se acostumbra en trabajos etnobiológicos y lingüísticos de nivel regional y global dedicados a estudiar la terminología asociada a la naturaleza (cfr. Mapes 
et al., 1981; Berlin, 1992; Ellen, 2000; Messineo \& Cúneo, 2007; Messineo, 2009; Messineo \& Tacconi, 2010; Suárez, 2010, 2011, 2014).

Por último, el criterio de validación de datos empleado fue que al menos dos personas proveyeran la misma información, y/o que fuera registrado directamente por el autor mediante observación participante, y/o que fuera encontrado en la bibliografía consultada. En los casos en que un dato fue referido por una sola persona, se evaluó en forma minuciosa las características del dato y del informante, el contexto en el que fue mencionado, así como el contenido del texto de la entrevista en el que aparece, para consignarlo como válido.

\section{Resultados}

Los hongos desde la perspectiva del criollo serrano

En este apartado se exponen los resultados relativos a los nombres vernáculos de los hongos, las motivaciones de los mismos, y a las denominaciones y percepciones de sus partes. Asimismo se realiza una aproximación al concepto de "hongo" de los criollos y se describen ciertas agrupaciones o categorías vernáculas en las que los serranos reúnen y clasifican los ejemplares estudiados. Para el desarrollo de estos tópicos, se utilizó la información recogida en torno a los 48 especímenes fúngicos recolectados durante la investigación, correspondientes a 31 especies, que pertenecen a 15 familias (Tabla 1 ).

\section{Nombres vernáculos}

Se registró un total de 26 nombres vernáculos aplicados a 30 especies fúngicas (Tabla 1). Solamente para la especie Parasola plicatilis no se registró ningún nombre, ya que los campesinos mostraron un total desconocimiento del hongo, refiriéndose al ejemplar recolectado como un "pastito" nomás, remarcando que no posee nombre. El resto de las especies estudiadas fueron nombradas con al menos uno de los siguientes nombres y cuyas motivaciones, que fueron brindadas por los propios yuyeros, se explican a continuación de cada uno de ellos:

"Barba de piedra" (Usnea amblyoclada, U. angulata): porque sale de las piedras (su sustrato son rocas) y el talo se asemeja a la barba de una persona, tanto por su morfología general como porque si es retirada vuelve a crecer (Fig. 2 A). Es el único nombre citado por todos los entrevistados para las especies mencionadas.

"Cascarita de espinillo" (Gloeophyllum striatum, Parmotrema reticulatum, Punctelia microsticta): porque la morfología general y/o color del talo o de la fructificación es similar a la cáscara (corteza) del 'espinillo' Acacia caven (Molina) Molina, que es su sustrato y se mimetiza con él.

"Cascarita de molle" (Schizophyllum commune): porque la morfología general del cuerpo fructífero es similar a la cáscara (corteza) del 'molle' (Lithraea molleoides), es de menor tamaño que las "florcitas de molle" (vide infra) y el basidioma no se destaca notoriamente de la superficie del sustrato.

"Cascarita de palo" (Byssomerulius corium, Canomaculina pilosa, Gloeophyllum striatum, Parmotrema praesorediosum, Parmotrema reticulatum, Punctelia microsticta, Schizophyllum commune, Truncospora sp.): porque la morfología general y/o color del talo o del cuerpo de fructificación es similar a la cáscara de los palos (árboles o arbustos), que son su sustrato.

"Cascarita de piedra" (Parmotrema reticulatum) porque por su morfología general y color el talo casi no se distingue de la superficie de la roca (por ser pequeño y no sobresalir mucho de la superficie).

"Cascarita de tala" (Byssomerulius corium): porque la morfología general de la fructificación es similar a la cáscara del 'tala' (Celtis ehrenbergiana (Klotzsch) Liebm.), que es su sustrato, y porque no sobresale mucho de la superficie del mismo.

"Cascarita de tala falso" (Canomaculina pilosa, Parmotrema praesorediosum, Parmotrema reticulatum, Truncospora sp.): porque la morfología general del talo o de la fructificación es similar a la cáscara del 'tala falso' (Bougainvillea stipitata Griseb.), que es su sustrato.

"Florcita de chilca" (Pycnoporus sanguineus): porque salen en (crecen sobre) las 'chilcas' (Flourensia oolepis S.F. Blake), y tienen colores que permiten diferenciarlos fácilmente del sustrato sobre el que se desarrollan. 
Tabla 1. Listado de las especies fúngicas estudiadas ordenadas alfabéticamente por familia, género y especie.

Para cada una se incluyen sus nombres científicos y vernáculos, datos sobre su ecología y los números de

voucher, fecha y lugar de recolección. Referencias: Alim= uso alimenticio, DMOS= degradador de materia

orgánica del suelo, $\mathrm{DM}=$ degradador de madera, $\mathrm{HL}=$ hongo liquenizado, $\mathrm{M}=$ micorrícico, Med= uso medicinal,

NU= ningún uso, LB= Loma Bola, LP= La Paz, Ornam= uso ornamental, Tin= uso tintóreo, Vet= uso veterinario.

\begin{tabular}{|c|c|c|c|}
\hline $\begin{array}{c}\text { FAMILIA/ } \\
\text { Nombre Científico }\end{array}$ & Nombre Vernáculo & Ecología/Uso & $\begin{array}{c}\text { Voucher, fecha } \\
\text { y lugar (col. } \\
\text { M. Flamini) }\end{array}$ \\
\hline \multicolumn{4}{|l|}{ AGARICACEAE } \\
\hline Agaricus spp. & $\begin{array}{l}\text { Hongo blanco } \\
\text { Hongo del diablo } \\
\text { Hongo de tierra } \\
\text { Hongo veneno }\end{array}$ & $\begin{array}{l}\text { DMOS, suelo en } \\
\text { diferentes ambientes. NU. }\end{array}$ & $\begin{array}{l}\text { 23: 24/01/12, LB; } \\
\text { 49: 22/02/13, LB }\end{array}$ \\
\hline Bovista cunninghamii Kreisel & $\begin{array}{l}\text { Hongo del diablo } \\
\text { Polvillo del diablo }\end{array}$ & $\begin{array}{l}\text { DMOS, suelo en áreas } \\
\text { abiertas. Med, Vet. }\end{array}$ & 52: 24/02/13, LP \\
\hline $\begin{array}{l}\text { Calvatia cyathiformis } \\
\text { (Bosc) Morgan }\end{array}$ & $\begin{array}{l}\text { Hongo del diablo } \\
\text { Polvillo del diablo }\end{array}$ & $\begin{array}{l}\text { DMOS, suelo en áreas } \\
\text { abiertas. Med, Vet. }\end{array}$ & $54: 25 / 02 / 13$, LB \\
\hline Calvatia fragilis (Quél.) Morgan & $\begin{array}{l}\text { Hongo del diablo } \\
\text { Polvillo del diablo }\end{array}$ & $\begin{array}{l}\text { DMOS, suelo en áreas } \\
\text { abiertas. Med, Vet. }\end{array}$ & 53: 25/02/13, LB \\
\hline $\begin{array}{l}\text { Disciseda candida } \\
\text { (Schwein.) Lloyd }\end{array}$ & $\begin{array}{l}\text { Hongo del diablo } \\
\text { Polvillo del diablo }\end{array}$ & $\begin{array}{l}\text { DMOS, suelo en áreas } \\
\text { abiertas. Med, Vet. }\end{array}$ & 1: 18/01/12, LP \\
\hline $\begin{array}{l}\text { Mycenastrum corium } \\
\text { (Guers.) Desv. }\end{array}$ & $\begin{array}{l}\text { Hongo del diablo } \\
\text { Polvillo del diablo }\end{array}$ & $\begin{array}{l}\text { DMOS, suelo en áreas } \\
\text { abiertas. Med, Vet. }\end{array}$ & $\begin{array}{l}\text { 2: 18/01/12, LP; } \\
\text { 58: 25/02/13, LB }\end{array}$ \\
\hline $\begin{array}{l}\text { Parasola plicatilis (Curtis) } \\
\text { Redhead, Vilgalys \& Hopple }\end{array}$ & & $\begin{array}{l}\text { DMOS, suelo en } \\
\text { áreas abiertas. NU. }\end{array}$ & 4: 19/01/12, LP \\
\hline \multicolumn{4}{|l|}{ BOLETINELLACEAE } \\
\hline $\begin{array}{l}\text { Phlebopus bruchii (Speg.) } \\
\text { Heinem. \& Rammeloo }\end{array}$ & $\begin{array}{l}\text { Hongo de coco } \\
\text { Hongo de comer } \\
\text { Hongo de molle }\end{array}$ & $\begin{array}{l}\text { DMOS, áreas boscosas } \\
\text { de 'molle' y 'coco'. Alim. }\end{array}$ & $\begin{array}{l}\text { 55: 28/02/13, LB; } \\
\text { 57: 10/02/13, LB }\end{array}$ \\
\hline \multicolumn{4}{|l|}{ GANODERMATACEAE } \\
\hline Ganoderma resinaceum Boud. & $\begin{array}{l}\text { Florcita de molle } \\
\text { Hongo de molle } \\
\text { Hongo de palo }\end{array}$ & $\begin{array}{l}\mathrm{DM} \text {, base de árboles } \\
\text { nativos muertos o } \\
\text { vivos. Ornam. }\end{array}$ & 44: 02/04/12, LB \\
\hline \multicolumn{4}{|l|}{ GEASTRACEAE } \\
\hline $\begin{array}{l}\text { Myriostoma coliforme } \\
\text { (Dicks.) Corda }\end{array}$ & $\begin{array}{l}\text { Hongo del diablo } \\
\text { Polvillo del diablo }\end{array}$ & $\begin{array}{l}\text { DMOS, áreas arbustivas } \\
\text { o boscosas. Med, Vet. }\end{array}$ & 51: 24/02/13, LP \\
\hline \multicolumn{4}{|l|}{ GLOEOPHYLLACEAE } \\
\hline Gloeophyllum striatum (Fr.) Murrill & $\begin{array}{l}\text { Cascarita de espinillo } \\
\text { Hongo de espinillo } \\
\text { Hongo de palo }\end{array}$ & $\begin{array}{l}\text { DM, troncos y ramas } \\
\text { en pie o caídos, vivos } \\
\text { o muertos. NU. }\end{array}$ & 8: 23/01/12, LB \\
\hline \multicolumn{4}{|l|}{ HYMENOCHAETACEAE } \\
\hline $\begin{array}{l}\text { Fuscoporia wahlbergii (Fr.) } \\
\text { T. Wagner \& M. Fisch. }\end{array}$ & Hongo de palo & DM, tronco en pie. NU. & 5: 20/01/12, LP \\
\hline Inonotus rickii (Pat.) D.A. Reid & $\begin{array}{l}\text { Florcita de espinillo } \\
\text { Florcita de molle } \\
\text { Hongo de espinillo } \\
\text { Hongo de molle } \\
\text { Hongo de palo }\end{array}$ & $\begin{array}{l}\text { DM, troncos y ramas } \\
\text { en pie o caídos, vivos } \\
\text { o muertos. NU. }\end{array}$ & $\begin{array}{l}36,37,42: \\
02 / 04 / 12, \text { LB }\end{array}$ \\
\hline Phellinus rimosus (Berk.) Pilát & $\begin{array}{l}\text { Florcita de tusca } \\
\text { Hongo de palo } \\
\text { Hongo de tusca }\end{array}$ & DM, troncos en pie. NU. & 18: 23/01/12, LB \\
\hline
\end{tabular}


Bol. Soc. Argent. Bot. 50 (3) 2015

\begin{tabular}{|c|c|c|c|}
\hline $\begin{array}{c}\text { FAMILIA/ } \\
\text { Nombre Científico }\end{array}$ & Nombre Vernáculo & Ecología/Uso & $\begin{array}{l}\text { Voucher, fecha } \\
\text { y lugar (col. } \\
\text { M. Flamini) }\end{array}$ \\
\hline \multicolumn{4}{|l|}{ PARMELIACEAE } \\
\hline $\begin{array}{l}\text { Canomaculina pilosa } \\
\text { (Stizenb.) Elix \& Hale }\end{array}$ & $\begin{array}{l}\text { Cascarita de tala falso } \\
\text { Florcita de espinillo }\end{array}$ & $\begin{array}{l}\text { HL, Corticícola, } \\
\text { folioso. NU. }\end{array}$ & $\begin{array}{l}\text { 62: 23/01/12, LB; } \\
\text { 65: 02/04/12, LB }\end{array}$ \\
\hline $\begin{array}{l}\text { Parmotrema praesorediosum } \\
\text { (Nyl.) Hale }\end{array}$ & Cascarita de tala falso & $\begin{array}{l}\text { HL, Corticícola, } \\
\text { folioso. NU. }\end{array}$ & 61: 23/01/12, LB \\
\hline $\begin{array}{l}\text { Parmotrema reticulatum } \\
\text { (Taylor) M. Choisy }\end{array}$ & $\begin{array}{l}\text { Cascarita de espinillo } \\
\text { Cascarita de la piedra } \\
\text { Cascarita de tala falso } \\
\text { Florcita de espinillo } \\
\text { Florcita de la piedra }\end{array}$ & $\begin{array}{l}\text { HL, Corticícola, } \\
\text { folioso. NU. }\end{array}$ & $\begin{array}{l}\text { 6: 23/01/12, LP; } \\
\text { 7, 17: 23/01/12, LB }\end{array}$ \\
\hline $\begin{array}{l}\text { Punctelia microsticta } \\
\text { (Müll. Arg.) Krog }\end{array}$ & Cascarita de espinillo & $\begin{array}{l}\text { HL, Corticícola, } \\
\text { folioso. NU. }\end{array}$ & 60: 23/01/12, LP \\
\hline Usnea amblyoclada Müll. Arg. & Barba de piedra & $\begin{array}{l}\text { HL, Saxícola, fruticuloso. } \\
\text { Med, Tin, Vet. }\end{array}$ & $\begin{array}{l}\text { 27: 25/01/12, LB; } \\
\text { 59: 25/02/13, LB }\end{array}$ \\
\hline Usnea angulata Ach. & Barba de piedra & $\begin{array}{l}\text { HL, Saxícola, fruticuloso. } \\
\text { Med, Tin, Vet. }\end{array}$ & 63: 02/04/12, LB \\
\hline \multicolumn{4}{|l|}{ PHANEROCHAETACEAE } \\
\hline $\begin{array}{l}\text { Byssomerulius corium } \\
\text { (Pers.) Parmasto }\end{array}$ & Cascarita de tala & DM, árbol en pie. NU. & 10: 23/01/12, LB \\
\hline \multicolumn{4}{|l|}{ POLYPORACEAE } \\
\hline Funalia gallica (Fr.) Ryvarden & $\begin{array}{l}\text { Florcita de espinillo } \\
\text { Florcita de molle } \\
\text { Hongo de espinillo } \\
\text { Hongo de molle } \\
\text { Hongo de palo }\end{array}$ & $\begin{array}{l}\text { DM, ramas muertas de } \\
\text { varias especies arbustivas } \\
\text { y arbóreas. NU. }\end{array}$ & $\begin{array}{l}\text { 20: 23/01/12, LB; } \\
\text { 40: 02/04/12, LB }\end{array}$ \\
\hline Pycnoporus sanguineus (L.) Murrill & $\begin{array}{l}\text { Florcita de chilca } \\
\text { Florcita de molle } \\
\text { Hongo de chilca } \\
\text { Hongo de molle } \\
\text { Hongo de palo }\end{array}$ & $\begin{array}{l}\text { DM, ramas muertas } \\
\text { caídas. NU. }\end{array}$ & $\begin{array}{l}\text { 30: 26/01/12, LB; } \\
\text { 43: 02/04/12, LB }\end{array}$ \\
\hline Trametes hirsuta (Wulfen) Lloyd & $\begin{array}{l}\text { Florcita de molle } \\
\text { Hongo de molle } \\
\text { Hongo de palo }\end{array}$ & $\begin{array}{l}\text { DM, ramas muertas } \\
\text { caídas. NU. }\end{array}$ & 41: 02/04/12, LB \\
\hline Truncospora sp. & Cascarita de tala falso & $\begin{array}{l}\text { DM, tocones o ramas } \\
\text { muertas aún adheridas } \\
\text { al árbol. NU. }\end{array}$ & 16: 23/01/12, LB \\
\hline \multicolumn{4}{|l|}{ RAMALINACEAE } \\
\hline $\begin{array}{l}\text { Ramalina celastri (Spreng.) } \\
\text { Krog \& Swinscow }\end{array}$ & Florcita de espinillo & $\begin{array}{l}\text { HL, Corticícola, } \\
\text { fruticuloso. NU. }\end{array}$ & 38: 02/04/12, LB \\
\hline \multicolumn{4}{|l|}{ SCHIZOPHYLLACEAE } \\
\hline Schizophyllum commune Fr. & $\begin{array}{l}\text { Cascarita de molle } \\
\text { Hongo de molle } \\
\text { Hongo de palo }\end{array}$ & $\begin{array}{l}\text { DM, ramas muertas } \\
\text { caídas o aún adheridas } \\
\text { al árbol. NU. }\end{array}$ & 15: 23/01/12, LB \\
\hline \multicolumn{4}{|l|}{ SCLERODERMATACEAE } \\
\hline Scleroderma bovista Fr. & $\begin{array}{l}\text { Hongo del diablo } \\
\text { Polvillo del diablo }\end{array}$ & $\begin{array}{l}\text { DMOS, áreas } \\
\text { abiertas. Med, Vet. }\end{array}$ & 45: 03/04/12, LB \\
\hline \multicolumn{4}{|l|}{ STEREOCAULACEAE } \\
\hline Lepraria sp. & Florcita de espinillo & $\begin{array}{l}\text { HL, Corticícola, } \\
\text { crustoso. NU. }\end{array}$ & 64: 02/04/12, LB \\
\hline
\end{tabular}




\begin{tabular}{|c|c|c|c|}
\hline $\begin{array}{c}\text { FAMILIA/ } \\
\text { Nombre Científico }\end{array}$ & Nombre Vernáculo & Ecología/Uso & $\begin{array}{l}\text { Voucher, fecha } \\
\text { y lugar (col. } \\
\text { M. Flamini) }\end{array}$ \\
\hline \multicolumn{4}{|l|}{ STROPHARIACEAE } \\
\hline $\begin{array}{l}\text { Gymnopilus chrysopellus } \\
\text { (Berk. \& M.A. Curtis) Murrill }\end{array}$ & Hongo de palo & $\begin{array}{l}\mathrm{DM} \text {, tocones o ramas } \\
\text { muertas. NU. }\end{array}$ & 48: 21/02/13, LB \\
\hline \multicolumn{4}{|l|}{ SUILLACEAE } \\
\hline Suillus granulatus (L.) Roussel & $\begin{array}{l}\text { Hongo de pino } \\
\text { Hongo de comer }\end{array}$ & $\begin{array}{l}\text { M, asociado a } \\
\text { plantaciones de } \\
\text { Pinus spp. Alim. }\end{array}$ & $\begin{array}{l}\text { 26, 31, 32: } \\
\text { 25/01/12, LB; } \\
\text { 35: 02/04/12, LB; } \\
\text { 46, 47: 03/04/12, LB; } \\
\text { 50: 01/03/13, LB }\end{array}$ \\
\hline
\end{tabular}

"Florcita de espinillo" (Canomaculina pilosa, Funalia gallica, Inonotus rickii, Lepraria sp., Parmotrema reticulatum, Ramalina celastri): porque salen en los 'espinillos' (Acacia caven), $\mathrm{y}$ tienen colores y/o tamaños que permiten diferenciarlos fácilmente del sustrato sobre el que se desarrollan.

"Florcita de molle" (Funalia gallica, Ganoderma resinaceum, Inonotus rickii, Pycnoporus sanguineus, Trametes hirsuta): porque salen en los 'molles' (Lithraea molleoides), y tienen colores y tamaños que permiten diferenciarlos fácilmente del sustrato sobre el que se desarrollan.

"Florcita de palo" (Canomaculina pilosa, Funalia gallica, Ganoderma resinaceum, Inonotus rickii, Lepraria sp., Parmotrema reticulatum, Phellinus rimosus, Pycnoporus sanguineus, Ramalina celastri, Trametes hirsuta): porque salen en los palos (árboles o arbustos) y tienen colores y/o tamaños que permiten diferenciarlos fácilmente del sustrato sobre el que se desarrollan.

"Florcita de piedra" (Parmotrema reticulatum) porque crecen sobre piedras, y porque por su forma (talo fruticuloso) sobresalen y se diferencian del sustrato sobre el que se desarrollan.

"Florcita de tusca" (Phellinus rimosus): porque salen en las 'tuscas' (Acacia aroma Gillies ex Hook. \& Arn.), y tienen un tamaño que permiten diferenciarlos fácilmente del sustrato sobre el que se desarrollan.

"Hongo blanco" (Agaricus spp.): porque es un "hongo" de color blanco.

"Hongo de chilca" (Pycnoporus sanguineus): porque son "hongos" que crecen en la madera de la 'chilca' (Flourensia oolepis).
"Hongo de coco" (Phlebopus bruchii): porque son "hongos" que crecen bajo la sombra del 'coco' (Zanthoxylum coco) o brotan de sus raíces.

"Hongo de comer" (Phlebopus bruchii, Suillus granulatus): porque son "hongos" que se pueden comer.

"Hongo de espinillo" (Funalia gallica, Gloeophyllum striatum, Inonotus rickii): porque son "hongos" que crecen en la madera del 'espinillo' (Acacia caven).

"Hongo del diablo" (Agaricus spp., Bovista cunninghamii, Calvatia cyathiformis, Calvatia fragilis, Disciseda candida, Mycenastrum corium, Myriostoma coliforme, Scleroderma bovista): son considerados "hongos", de ahí el primer término que compone el nombre. La gente dice desconocer el motivo preciso por el cual se denominan "del diablo"; algunos apuntan que porque son de color oscuro o porque si se mezcla con la sangre hace mal (el contacto de la gleba con una herida abierta tendría efectos nocivos para los humanos). Dos entrevistados comentaron que a Agaricus spp. se le aplica este nombre porque es un hongo que hace mal, es tóxico para los humanos.

"Hongo de molle" (Funalia gallica, Ganoderma resinaceum, Inonotus rickii, Phlebopus bruchii, Pycnoporus sanguineus, Schizophyllum commune, Trametes hirsuta): porque son "hongos" que crecen bajo la sombra o brotan de la madera o de las raíces del 'molle' ( $L$. molleoides).

"Hongo de palo" (Funalia gallica, Fuscoporia wahlbergii, Ganoderma resinaceum, Gloeophyllum striatum, Gymnopilus chrysopellus, Inonotus rickii, Phellinus rimosus, 
Suillus granulatus, Pycnoporus sanguineus, Trametes hirsuta, Phlebopus bruchii, Schizophyllum commune): porque son "hongos" que están vinculados a los palos, ya sea porque crecen bajo la sombra o de la madera o de las raíces de los palos.

"Hongo de pino" (Suillus granulatus): porque son "hongos" que crecen bajo la sombra del "pino honguero' (Pinus halepensis Mill.) o emergen de sus raíces (Fig. 2 B).

"Hongo de tierra" (Agaricus spp.): porque es un "hongo" que sale de la tierra (suelo).

"Hongo de tusca" (Phellinus rimosus): porque son "hongos" que crecen en la madera de la 'tusca' (Acacia aroma).

"Hongo veneno" (Agaricus spp.): porque es un "hongo" que tiene veneno, es considerado tóxico (Fig. 2 C).

"Polvillo del diablo" (Bovista cunninghamii, Calvatia cyathiformis, Calvatia fragilis, Disciseda candida, Mycenastrum corium,
Myriostoma coliforme, Scleroderma bovista): todos coinciden en que el término "polvillo" hace referencia directa al polvito seco como harina (gleba madura pulverulenta) que tienen los "hongos" incluidos bajo esta denominación. Las siete especies fúngicas que fueron nombradas de esta manera también son llamadas "hongo del diablo". De la misma manera que sucede con ese nombre, la mayoría de los entrevistados desconoce por qué se dice que el "polvillo" es "del diablo". Aún admitiendo su desconocimiento, algunos conjeturan que podría ser por su color oscuro o porque hacen mal (serían tóxicos) (Fig. 2 D y E).

Las partes de un hongo: el hongo es uno

En general, cuando los entrevistados fueron consultados directamente por los nombres de partes o estructuras de los hongos, ninguno calificó o dio referencias particulares para ellas; por el contrario, todos afirmaron que los hongos no tienen partes, el
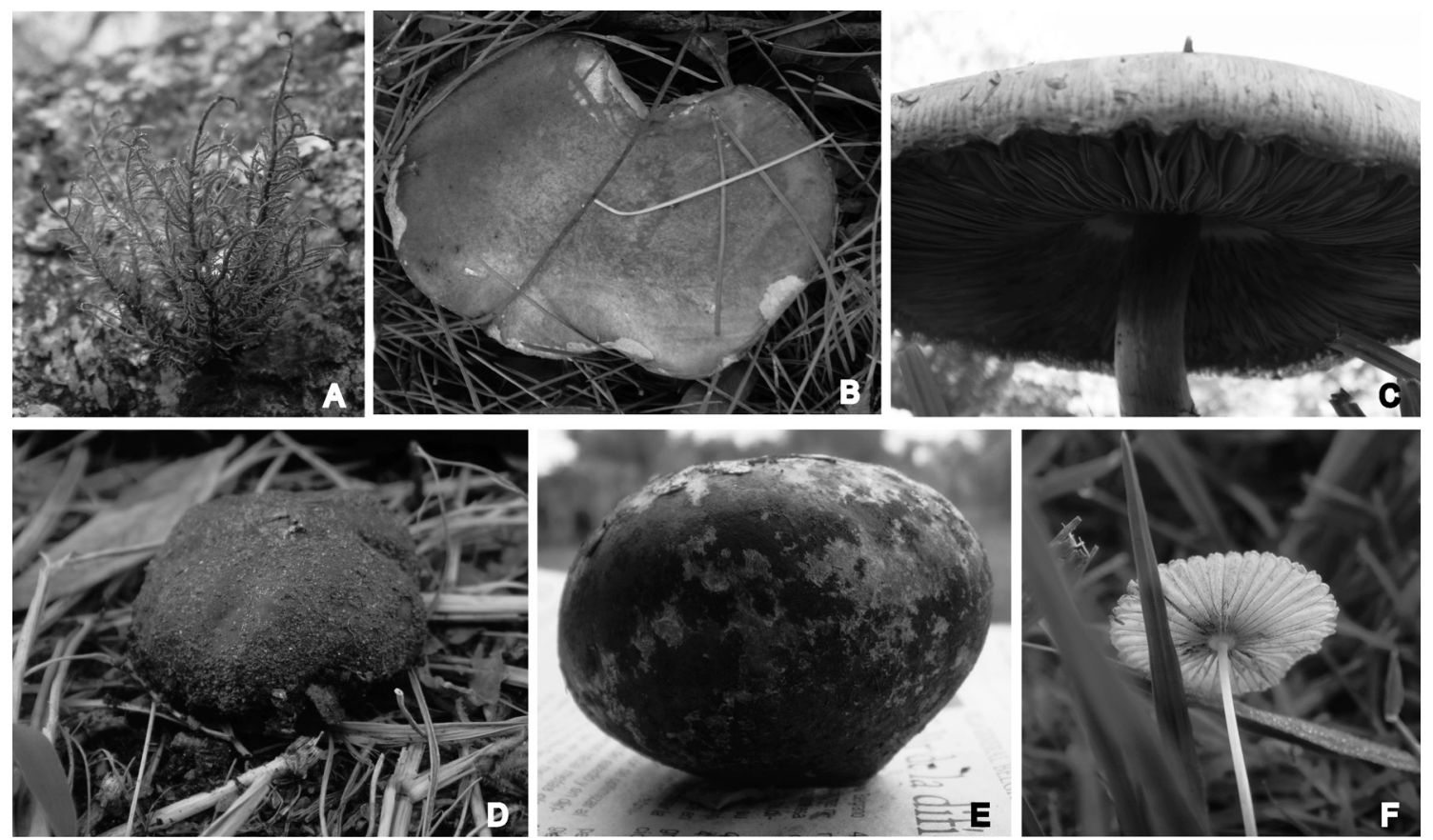

Fig. 2. Algunos de los hongos recolectados durante los recorridos por el bosque. "Barba de piedra", Usnea sp. (A); "Hongo de pino", Suillus granulatus (B); "Hongo veneno", Agaricus sp. (C); "Polvillo del diablo", Disciseda candida (D); "Polvillo del diablo", Mycenastrum corium (E); Parasola plicatilis (F). Fotos: M. Flamini. 


\section{Flamini et al. - Nombres y clasificaciones de los hongos de La Paz, Córdoba}

hongo es uno. Sin embargo, al hablar de otros temas (recetas culinarias, preparaciones medicinales, recolección, etc.) surgieron espontáneamente algunas expresiones o términos específicos para ciertas partes, que los entrevistados brindaron trabajando con los ejemplares en la mano. Así, si bien el himenóforo no posee un nombre vernáculo que lo distinga del resto de la fructificación, sí es una parte distintiva y muy particular a los ojos de los criollos serranos, que les ayuda a definir si un espécimen es un "hongo" y a distinguir entre diferentes especies de "hongos". Según los informantes, el himenóforo puede ser con huequitos todo parejo, como una esponja (himenóforo poroide) o como un libro, con tiritas largas (himenóforo lamelar). Esta diferenciación es la que principalmente utilizan para distinguir a los hongos comestibles Phlebopus bruchii y Suillus granulatus, con himenóforo poroide, de Agaricus spp., que es considerado tóxico y tiene laminillas.

Otra parte recurrentemente destacada durante las entrevistas que trataban sobre la recolección de los hongos comestibles $P$. bruchii y $S$. granulatus, es el palito (estípite) que es la sección desde la que se los toma con los dedos para recogerlos. Por otra parte, al hablar sobre las distintas clases de "hongos" que conocen, dos entrevistados se refirieron al píleo de dichas especies y de Agaricus spp. como el platito que está arriba.

Hablando sobre recetas con hongos se mencionó la piel/pielcita (cutícula del píleo). Esta parte fue citada para los hongos alimenticios, sobre todo para el "hongo de pino" (S. granulatus) al cual se le retira la cutícula para preparar una receta de hongos frescos y para conservarlos secos. Fue también hablando sobre recetas y maneras de secar este hongo para su almacenamiento, que surgieron los términos corazón (contexto) y barba (estrato de tubos del himenóforo).

Varias partes de los "polvillo del diablo" fueron nombradas en forma descriptiva al estudiarlos: todos los entrevistados consideran que los "polvillo del diablo" se distinguen por ser bolitas o pelotitas que en su interior contienen un polvito o polvo (gleba pulverulenta) de color marrón oscuro o negro, recubierto por una cáscara o piel (peridio). De todas formas, al igual que con los demás ejemplares estudiados, cuando se realizaba una pregunta directa acerca de si alguna estructura específica tenía nombre, la respuesta era siempre negativa. Las mismas respuestas se obtuvieron sobre las "barba de piedra", pero cuando los informantes hablaban acerca de formas de preparación de infusiones con estos líquenes, utilizaban el término plantita para referirse al talo de cada ejemplar.

\section{El concepto vernáculo de "hongo"}

De acuerdoa la perspectiva de los criollos serranos, los "hongos" presentan ciertas características morfológicas y ecológicas propias que los definen y conforman como un grupo de organismos independiente, y otras que específicamente los diferencian de plantas (vegetales que la gente cultiva en la casa, son mayoritariamente especies exóticas pero también son consideradas de este modo especies nativas utilizadas en agricultura) y yuyos (vegetales herbáceos que crecen fuera del ámbito doméstico) ${ }^{3}$.

En cuanto a las cualidades ecológicas, los entrevistados explican que todos los "hongos" necesitan humedad para salir y crecer, la cual obtienen exclusivamente de la tierra (suelo) o de los palos (árboles o arbustos), según cuál sea su sustrato. Por este motivo, manifiestan que la mayoría de los "hongos" aparecen y crecen solamente después de las lluvias. Es interesante destacar que cuando los campesinos hablan de los palos como sustrato, hacen referencia a árboles o arbustos ya sea vivos o muertos, en pie o caídos. Respecto de la morfología, en principio las características que para los serranos definen a un "hongo" y a la vez lo distinguen claramente de un vegetal, son la presencia de un himenóforo visible a simple vista $y$, aunque de menor trascendencia que la anterior, la presencia de un píleo y/o de un estípite. De todas formas, estas características -por más que resulten muy importantes y ayuden a una rápida determinación- no son excluyentes, ya que ciertos ejemplares son considerados "hongos" a pesar de no poseer las estructuras morfológicas mencionadas. Es el caso de los "polvillo del diablo" que se conciben como "hongos" porque salen de la humedad de la tierra y porque, a pesar de no tener pie, píleo ni himenóforo, su forma y colores típicos ("como una bolita blanca o marrón

\footnotetext{
${ }^{3}$ Aunque no fue un tema particular de interés para la investigación, los datos obtenidos sugieren que entre los serranos existen estas dos clases de vegetales: "plantas" y "yuyos", que por su descripción coinciden en términos generales con lo registrado por Scarpa (2012b) para los criollos de Salta y Formosa.
} 
oscura o negra") permiten distinguirlos fácilmente de plantas o yuyos; más aún, sostienen que los "polvillo del diablo" se desparraman (dispersan) cuando al estar maduros el viento se lleva el polvito seco marrón, a diferencia de los vegetales que se desparraman mediante semillas. Empero, dos entrevistados afirmaron que los "hongos" son aquellos que salen exclusivamente de la tierra y no de otro sustrato, de lo contrario son "florcitas" o "cascaritas" de los palos o piedras, aún cuando cuenten con alguna de las otras características distintivas mencionadas anteriormente. En sentido inverso, las "florcitas" y "cascaritas" no serían consideradas en su totalidad como "hongos", pero tampoco se las puede considerar como categorías absolutamente independientes.

Para los yuyeros, las "barba de piedra" (Usnea amblyoclada y $U$. angulata) no son plantas porque salen en el monte y no en el ámbito doméstico, ni yuyos porque salen de las piedras y no de la tierra ${ }^{4}$. Tampoco son consideradas "hongos", porque salen por la humedad que se acumula en la piedra, mientras que los "hongos" salen de los palos o de la tierra, nunca de las rocas. Vale mencionar aquí que dos entrevistados consideran que la "barba de la piedra" sí es un "yuyo" por la forma que presenta y porque, de acuerdo a uno de ellos, tiene raices con las que se agarra a la piedra y hojitas largas que sobresalen de la piedra.

\section{Categorías vernáculas de los hongos estudiados}

Para comenzar, como explican los entrevistados, los "hongos" pueden clasificarse en "hongos de palo" y "hongos de tierra" según obtengan la humedad de los palos o de la tierra respectivamente.

La categoría "hongos de palo" incluye a dos categorías de "hongos" subordinadas: los "hongos de comer" y los "hongos de palo verdaderos". Estas se diferencian entre sí por el uso alimenticio que se les da a los primeros, y porque los segundos, además de no tener utilidad alguna para los criollos serranos, emergen directamente del palo a diferencia de los alimenticios que, si bien están asociados al palo, emergen desde la tierra. Todos los entrevistados concuerdan en que los "hongos de comer" (Phlebopus bruchii y Suillus granulatus) tienen un vínculo con el palo, de ahí que se los llame a veces "hongos de palo" y se incluyan en la categoría

${ }^{4} \mathrm{De}$ acuerdo a los entrevistados tanto "plantas" como "yuyos" crecen en la tierra y no sobre otro sustrato. homónima. Sin embargo, la relación específica que mantienen con el palo es más difusa que la de los "hongos de palo verdaderos", y no hay acuerdo total entre los entrevistados sobre la cuestión. Para algunos, los "hongos de comer" están asociados con las raíces de ciertos árboles que les proveen la humedad y la fuerza que necesitan para florecer (brotar) de la tierra, mientras que otros sostienen que no están ligados directamente al palo ya que salen por la humedad del suelo o del monte, pero destacan que siempre salen cerca o bajo la sombra de algún 'molle' (Lithraea molleoides) o 'coco' (Zanthoxylum coco), siendo ésta la única asociación que existe entre estos organismos. De cualquier manera, tanto unos como otros creen que es necesario que llueva, que se junte humedad y que luego salga el sol para que se levante un vapor del suelo y florezcan (emerjan las fructificaciones fúngicas).

Los "hongos de palo verdaderos" pueden nombrarse mediante la mera designación de "hongo de palo", o también pueden nombrarse mediante denominaciones más específicas. En este último caso, el nombre del hongo incluye información acerca de la especie vegetal sobre la que crece o a la cual está asociada. Así, si uno de estos hongos se encuentra creciendo en un 'espinillo' (Acacia caven), puede ser llamado "hongo de espinillo", si está sobre un 'tala' (Celtis ehrenbergiana) será "hongo de tala", y así sucesivamente.

En relación con esto, existe entre los entrevistados una clara e interesante divergencia de posturas en torno a dos de los nombres que se aplican a la especie P. bruchii: para la mayoría, "hongo de coco" $\mathrm{y}$ "hongo de molle" son sinónimos que refieren a un mismo "hongo", pero para otros cada nombre hace referencia a un "hongo" distinto, es decir, a dos etnoespecies diferentes. Los que sostienen que son dos etnoespecies justifican su postura argumentando que es de esa manera porque salen de dos árboles diferentes, por más que los basidiomas sean iguales morfológicamente. Los que sostienen que ambas denominaciones son sinónimos que referencian a una misma etnoespecie, plantean que es así porque son indistinguibles morfológicamente. Además, algunas de las personas que mantienen esta postura afirman que en realidad estos hongos no tienen vínculo directo con los árboles, pero que crecen cerca de 'molles' y 'cocos' porque hay más humedad en esos lugares que en la playa (áreas despejadas de vegetación leñosa). 


\section{Flamini et al. - Nombres y clasificaciones de los hongos de La Paz, Córdoba}

Los "hongos de palo verdaderos" (Funalia gallica, Fuscoporia wahlbergii, Ganoderma resinaceu, Gloeophyllum striatum, Gymnopilus chrysopellus, Inonotus rickii, Phellinus rimosus, Pycnoporus sanguineus, Schizophyllum commune, Trametes hirsuta) son más duros y resistentes que los "hongos de comer" y que los "hongos de tierra". Según los yuyeros, estas cualidades se las confiere la madera del palo donde crecen, que les transfiere su fuerza. Otra diferencia entre los "hongos de palo verdaderos" y los "hongos de comer" es que los primeros se crían con más tiempo (su crecimiento es más lento) pero necesitan menos humedad, mientras que los segundos salen y crecen rápido pero dependen mucho de la lluvia, son pura agua, por eso son más blanditos y se achican mucho cuando se secan. En este sentido, explican que al depender de las lluvias y la humedad, los "hongos de comer" tienen un tiempo, es decir, aparecen en una temporada determinada del año, mientras que los otros pueden brotar, crecer y permanecer durante todo el año e incluso por varios años.

Los "hongos de comer", al igual que los "hongos de palo verdaderos", también poseen algunas características que heredan del palo al que se asocian. En este sentido, sostienen que los "hongos de pino" son más blandos que los "hongos de coco" y/o los "hongos de molle" porque la madera del 'pino honguero' (Pinus halepensis) es más blanda que las otras. También se observó que algunas percepciones generales sobre los palos se trasladan a los hongos asociados a ellos, como el hecho de considerar que el "hongo de coco" o el "hongo de molle" es de mejor calidad y son mejor alimento que el "hongo de pino", simplemente porque el 'molle' y el 'coco' son mejores (en cuanto a su apreciación general) que el 'pino honguero'.

Por otro lado, los "hongos de la tierra", que nacen de la humedad de la tierra, son más blandos que los "hongos de palo", es decir que se pueden romper con más facilidad. En esta categoría se incluye a los "polvillo del diablo" (Bovista cunninghamii, Calvatia cyathiformis, Calvatia fragilis, Disciseda candida, Mycenastrum corium, Myriostoma coliforme, Scleroderma bovista) y al "hongo blanco" (Agaricus spp.). Además de las evidentes diferencias morfológicas existentes entre ambos grupos, los entrevistados dicen que los "polvillo del diablo" necesitan menos humedad para brotar porque por dentro es todo seco, por lo que no tiene un tiempo y se lo puede encontrar todo el año. Por su parte, el "hongo blanco" sí tiene un tiempo, que coincide con el de los "hongos de comer" dado que al igual que ellos necesita la humedad de las lluvias. Es importante aclarar que los "polvillo del diablo" no son considerados estacionales, pero a la vez los entrevistados sostienen que con las lluvias se los encuentra con mayor frecuencia, es decir, están todo el año pero abundan más en tiempos de lluvia. Una característica común a los "polvillo del diablo" y al "hongo blanco", es que pueden crecer en cualquier parte: en la playa, en el monte, al lado de una piedra.

En relación con los "polvillo del diablo", es importante destacar que aunque los entrevistados reconocen diferencias morfológicas entre ejemplares de distintas especies fúngicas y consideran que son "hongos" distintos, permanentemente aclaran que se relacionan estrechamente entre sí y que sirven para los mismos fines prácticos (medicinales y veterinarios), de ahí que se los agrupa a todos bajo la misma etiqueta nomenclatural. Tres entrevistados reconocieron inmediatamente a Calvatia cyathiformis como "el verdadero polvillo del diablo"; este dato indica que dicha especie podría ser el "polvillo del diablo" prototípico. Al describirlo, mencionan ciertos caracteres como particularidades de esta especie: el polvito (gleba) es muy abundante y de color café, y la fructificación tiene un tamaño grande, una forma particular, y la cáscara es de color marrón oscuro cuando está maduro y blanco cuando es más joven.

Por último, existen otras dos categorías vernáculas que agrupan a ciertas especies fúngicas estudiadas: las "cascaritas" y las "florcitas". Estas categorías incluyen otras más específicas, que se reflejan en los nombres vernáculos. Como se explicó anteriormente, de acuerdo a determinadas características del talo o cuerpo fructífero, los hongos serán considerados "cascaritas" o "florcitas" (si son achatadas y pegadas al sustrato o si se destacan del mismo por su tamaño, color o forma, respectivamente), y dependiendo del sustrato en que se encuentren serán de palo o de piedra (para estas categorías, esos son los dos únicos sustratos en los que se pueden desarrollar). Además, las especies que tienen como sustrato a los palos se pueden denominar de manera más específica según el árbol sobre el que crecen ("florcita de molle", "cascarita de tala", etc.). Entre las especies recolectadas, se incluyen bajo estas 
denominaciones generales a todos los líquenes, con excepción de Usnea spp. (Canomaculina pilosa, Lepraria sp., Parmotrema praesorediosum, Parmotrema reticulatum, Punctelia microsticta, Ramalina celastri), y a otros hongos (Byssomerulius corium, Funalia gallica, Ganoderma resinaceum, Gloeophyllum striatum, Inonotus rickii, Phellinus rimosus, Pycnoporus sanguineus, Schizophyllum commune, Trametes hirsuta, Truncospora sp.). Para los líquenes y las especies Truncospora sp. y Byssomerulius corium estas son las únicas categorías que los incluyen, a diferencia de las otras especies fúngicas que a su vez se incluyen entre los "hongos de palo".

Los entrevistados creen que tanto las "cascaritas de palo" como las "florcitas de palo" no hacen ningún daño o perjuicio al palo que les da origen. Asimismo, sostienen que los dos tipos no son una parte más del palo como sí lo son las flores o la corteza, sino que aparecen y crecen sobre el palo a partir de la humedad que se acumula en él, en particular, en el corazón del palo (duramen) o -para otros- en la cáscara del palo (corteza). En este sentido, algunos informantes proponen que las "florcitas" y "cascaritas" no son ni plantas ni yuyos, debido a que florecen de la humedad de los palos o piedras, mientras que las "plantas" y "yuyos" salen exclusivamente de la tierra; y tampoco todas se consideran "hongos", porque algunas especies no presentan ninguna de las características que los definen.

Algo similar ocurre con el último grupo de especies estudiadas, sobre las que se habló en detalle en la sección anterior: las "barba de piedra". Estas especies no se consideran "hongo", y por lo general tampoco planta o yuyo.

\section{Discusión}

\section{Los nombres de los hongos}

El conjunto de nombres vernáculos registrados no es ni pretende ser un listado exhaustivo de la miconimia de los campesinos serranos de La Paz y Loma Bola, y lógicamente no puede hacerse extensivo al común de la población de los campesinos de la zona. Sin embargo, su estudio minucioso sirve como punto de partida para dilucidar patrones nomenclaturales subyacentes y los sistemas de clasificación vernáculos.
En primer lugar, el análisis lingüístico de los micónimos muestra que todos los nombres registrados son compuestos (i.e. compuestos nominales), es decir, están formados por dos o más bases y que tanto semántica como formalmente conforman unidades léxicas indisolubles (Alcaraz Varó \& Martínez Linares, 1997; Booij, 2005). Esto no es de extrañar, dado que la composición es uno de los procedimientos más frecuentes y productivos de los que disponen las lenguas para la formación de nuevos nombres (Booij, 2005), lo cual es particularmente cierto para el español (Bustos Gisbert, 1986; Sánchez Méndez, 2009). Además, este fenómeno ha sido ampliamente registrado y analizado en la región de estudio en relación con la formación de nombres de plantas (fitónimos) en varias lenguas indígenas del Gran Chaco, como en toba, en maká y en wichí (Messineo \& Cúneo, 2007; Messineo, 2009; Messineo \& Tacconi, 2010; Suárez, 2010, 2011). También fue registrado para micónimos entre los wichís (Suárez, 2014).

De acuerdo con su estructura morfosintáctica ${ }^{5}$ encontramos cuatro tipos de compuestos nominales:

1) Nombre + GEN-Nombre.

De las cuatro, esta resulta la estructura más básica.

Ejemplo de glosa:

Hongo de chilca

hongo + de-chilca

hongo + GEN-chilca

Esta estructura la poseen los siguientes nombres: "hongo de chilca", "hongo de coco", "hongo de espinillo", "hongo de molle", "hongo de tusca", "hongo de palo", "hongo de tierra", "hongo del diablo", "barba de piedra", "hongo de comer".

\section{2) Nombre-DIM + GEN-Nombre}

Como puede verse, esta estructura es la estructura básica más el diminutivo (DIM).

\footnotetext{
${ }^{5}$ Abreviaturas utilizadas: GEN: genitivo, DIM: diminutivo, Adj: adjetivo, EVAL: adjetivo evaluativo, +: separa los constituyentes del compuesto, -: separa morfemas.
} 


\section{Flamini et al. - Nombres y clasificaciones de los hongos de La Paz, Córdoba}

Ejemplo de glosa:

Florcita de palo.

flor-cita + de-palo

flor-DIM + GEN-palo

Esta estructura la poseen los siguientes nombres: "florcita de palo", "cascarita de palo", "cascarita de espinillo", "cascarita de molle", "cascarita de piedra", "cascarita de tala", "florcita de chilca", "florcita de espinillo", "florcita de molle", "florcita de piedra", "florcita de tusca", "polvillo del diablo", "cascarita de tala falso".

\section{3) $[$ Nombre + GEN-Nombre $]+$ Adj}

El adjetivo se añade a la estructura básica. El Adj en este caso modifica a un compuesto entero, el cual se indica entre corchetes.

\section{Glosa:}

Hongo de palo verdadero

[hongo + de-palo] + verdadero

[hongo + GEN-palo] + EVAL

Esta estructura se observa en un solo caso: "hongo de palo verdadero".

4) Nombre + Adj

Ejemplo de glosa:

Hongo blanco ${ }^{6}$

hongo + blanco

Esta estructura la poseen los siguientes nombres: "hongo blanco", "hongo veneno".

Por otro lado, el análisis semántico de los micónimos indica que de acuerdo a su significado los nombres compuestos hacen referencia a:

- El sustrato sobre el que crecen: "barba de piedra",

"cascarita de espinillo", "cascarita de molle",

"Se podría "hilar más fino" y marcar el género, sólo para mostrar que hay concordancia entre ambos constituyentes:

hongo + blanc-o

hongo-MASC + blanco-MASC "florcita de chilca", "cascarita de piedra", "cascarita de tala", "cascarita de tala falso", "cascarita de palo", "florcita de espinillo", "florcita de molle", "florcita de palo", "florcita de piedra", "florcita de tusca", "hongo de chilca", "hongo de coco", "hongo de espinillo", "hongo de molle", "hongo de palo", "hongo de pino", "hongo de tierra", "hongo de tusca".

- La función social: "hongo de comer".

- El color de la fructificación entera y/o de alguna de sus partes: "hongo blanco", "hongo del diablo", "polvillo del diablo".

- La toxicidad: "hongo veneno", "hongo del diablo", "polvillo del diablo".

- Su aspecto, morfología o configuración: todos los nombres citados para los hongos estudiados implican en su definición características de este tipo.

La nomenclatura de los hongos de los campesinos serranos muestra que, más allá de las particularidades y diversidad de nombres, existen coincidencias con la forma en que lo hacen otros grupos humanos en otras partes del mundo. Así, que el nombre de un hongo haga referencia a la toxicidad, a la utilidad, al sustrato y/o a rasgos morfológicos es algo frecuente entre grupos indígenas de México ( $v . g$. Mapes et al., 1981; Moreno Fuentes et al., 2004; Ruán Soto et al., 2007; Grajales-Vásquez et al., 2008; Jiménez González, 2008), pobladores rurales de España (v. g. Fajardo et al., 2010; Velasco et al., 2011), comunidades indígenas de Venezuela (Zent et al., 2004), grupos indígenas de Argentina (Suárez, 2014), y pueblos indígenas de Indonesia (Ellen, 2008), por mencionar algunos. Ahora bien, el estudio semántico de los micónimos de los yuyeros muestra además que algunos nombres responden a un criterio más bien utilitario o que al menos refleja características significativas y de interés para los campesinos, mientras que otros siguen un criterio que expresa conocimientos más amplios sobre los macrohongos de la zona. Se pueden entonces proponer dos grandes grupos de nombres que responden a uno u otro criterio respectivamente: en el primero se agrupan 4 micónimos que tratan sobre la toxicidad y la función social, y en el segundo grupo 23 nombres que hacen referencia al sustrato, al color y a la morfología, aspecto o configuración. Queda entonces evidenciado que la 
mayoría de los nombres vernáculos otorgados es reflejo del conocimiento que poseen los serranos por los hongos de su entorno, más allá de cuestiones utilitaristas.

Haciendo un análisis general sobre la nomenclatura de los yuyeros en conjunto con otros datos obtenidos en el campo, se puede apreciar que de las 30 especies que tienen al menos un nombre, tan sólo 12 son utilizadas para algún fin (comestibles, medicinales, tintóreas, veterinarias y ornamentales) y una es considerada tóxica, por lo que el número de especies culturalmente relevante es menor (40\%) que el de las restantes 18 que no tienen ningún uso ni presentan algún interés práctico para la comunidad $(60 \%)^{7}$. En otras palabras, los campesinos serranos otorgan nombres tanto a especies con alguna significación cultural de nivel práctico como también a aquellas que no cuentan con un interés pragmático, reflejando en su nomenclatura tanto la visión "utilitarista" que propone Hunn (1982), como la "intelectualista" que sostiene Berlin (1992), en tanto que los nombres se otorgan también de acuerdo a las discontinuidades que observan y perciben en la naturaleza las comunidades humanas. Respecto de esto último, es preciso ahondar sobre el caso particular de los nombres "hongo de coco" y "hongo de molle" cuando refieren a la especie $P$. bruchii. Para algunos campesinos la diferencia en el sustrato es suficiente para considerar que ambos nombres hacen referencia a dos etnoespecies; otros (una clara mayoría) consideran que más allá del sustrato sobre el que se desarrollen los basidiomas, al no existir diferencias significativas en la morfología de los ejemplares -según su percepción-, los nombres son sinónimos aplicados a una misma etnoespecie. Entonces, para P. bruchii, estas "discontinuidades de la naturaleza" se conciben y clasifican según dos criterios que conviven en el seno de la cultura de los serranos, que cada individuo aplica según su propia percepción. En este punto, es preciso tener en cuenta que los que consideran que es una sola etnoespecie estén probablemente influenciados, por un lado por el hecho de que las herboristerías y otros comercios de la zona compran los hongos "de coco" o "de molle" como un mismo producto y, por otro,

${ }^{7}$ Como se mencionó anteriormente, la información aquí vertida forma parte de una investigación de mayor alcance en la que se obtuvieron datos sobre la toxicidad y utilidad de ciertos hongos que crecen en la zona, los cuales serán publicados en una contribución posterior. aunque no haya sido planteado directamente por los entrevistados, que $P$. bruchii es utilizado por todos los serranos para los mismos fines (alimenticios) y de la misma manera.

Por otra parte, todos los nombres estudiados se forman de similar manera a nivel morfosintáctico $y$, examinando estos datos junto con los resultados obtenidos sobre los agrupamientos vernáculos de los hongos, se observa que en ellos está codificada cierta información sobre la clasificación vernácula de las especies nombradas. Así, el primer término del compuesto (hongo, cascarita, florcita) es un hiperónimo que indica la categoría taxonómica vernácula en la que está incluida la especie nombrada, mientras que el segundo constituyente del compuesto brinda información sobre alguna cualidad sobresaliente del organismo: el sustrato sobre el que crece (de palo, de piedra, de vegetales específicos), la función social (de comer), la morfología o partes del talo (barba, polvillo), el color (blanco, del diablo) y/o la toxicidad que poseen (veneno, del diablo). De esta manera, por ejemplo, el micónimo "hongo de molle" indica que el organismo así nombrado es concebido por los campesinos como un "hongo", y además, que es un "hongo" que crece en un 'molle' (Lithraea molleoides).

Estos resultados sobre los patrones nomenclaturales encontrados en la miconimia de los campesinos de Traslasierra, permiten afirmar que las motivaciones subyacentes a los nombres de hongos son bastante transparentes si se los analiza lingüísticamente, es decir, los motivos que llevan a la gente a aplicar un nombre determinado a un hongo son fácilmente visibles al examinar lingüísticamente cada nombre ${ }^{8}$. Es de destacar que los entrevistados son por lo general conscientes de ellas (fueron explicitadas por ellos mismos), lo cual no necesariamente ocurre cuando se estudia la terminología asociada a la naturaleza, ya que las motivaciones originales de los nombres suelen estar en muchos casos lejos en el tiempo y con las generaciones se olvidan. Una excepción son los nombres "polvillo del diablo" y "hongo del diablo", ya que no está del todo claro el motivo por el cual se los califica vinculados con el diablo. Por el

${ }^{8}$ Por ejemplo, "hongo veneno" se aplica, según explican los entrevistados, a hongos que se consideran venenosos o tóxicos. Aún cuando no se contara con la explicación de los informantes, a través del análisis lingüístico se llegaría a la misma conclusión. 


\section{Flamini et al. - Nombres y clasificaciones de los hongos de La Paz, Córdoba}

momento, los datos sugieren que se relaciona a la toxicidad (que le atribuyen) o al color oscuro de la fructificación madura de algunos de estos hongos. Esto no sería raro, ya que el calificativo "del diablo" es aplicado en diversas culturas a organismos que son o que al menos se consideran tóxicos (RuánSoto et al., 2007; Velasco et al. 2011).

Por otro lado, como puede apreciarse en la Tabla 1, el $50 \%$ de los nombres vernáculos de hongos (13) refiere, cada uno, a una única especie fúngica estudiada, de modo que la otra mitad hace referencia a más de una. Que la mitad de los nombres sean polisémicos (su significado no es único, sino que el mismo nombre se aplica a más de una entidad), lleva a pensar que la distinción entre etnoespecies o especies nombradas bajo la misma etiqueta no es significativa para la vida cotidiana de los serranos, como sería el caso de los llamados "polvillo del diablo". Esta afirmación se podría sustentar en que les resulta indistinto, por ejemplo en el caso de los "polvillo del diablo", emplear una u otra especie a los fines utilitarios (medicinal y veterinario). Lo mismo ocurre con las "barba de piedra" (Usnea spp.) pero a diferencia del caso anterior no habría una especie prototípica o al menos no se han podido encontrar indicios que avalen esa hipótesis.

De cualquier manera, la explicación anterior no puede aplicarse a todos los hongos ya que ciertas denominaciones, aunque polisémicas, aluden casi siempre a una especie particular. Así sucede con Phlebopus bruchii que es llamado por los nombres: "hongo de coco" y "hongo de molle". El primer nombre es monosémico y hace referencia sólo a esta especie, pero el segundo es utilizado por los campesinos para referirse a varias especies de hongos que crecen sobre 'molles' ( $L$. molleoides). Sin embargo, cuando un campesino habla del "hongo de molle", casi siempre está haciendo referencia a $P$. bruchii. De la misma manera, aún cuando sólo se registró una única especie con el nombre "hongo de pino" (Suillus granulatus), considerando que en la zona existen otros hongos vinculados a los pinos (Domínguez \& Hernández Caffot, 2011), es válido suponer que más especies (aún no estudiadas) lleven el mismo nombre. Sin embargo, al igual que con P. bruchii, cuando los campesinos se refieren al "hongo de pino" la referencia inequívoca es a $S$. granulatus. En ambos casos, esta particularidad podría estar relacionada con la importancia que tienen estas especies para los campesinos serranos, en tanto que son recolectadas para la venta y para su propia alimentación.

Ahora bien, en forma inversa, se observa que sólo el 33\% de los taxones fúngicos (10 especies de 30 que llevan nombre vernáculo) posee, cada uno, sólo un nombre vernáculo, por lo que el restante $67 \%$ (20 especies) posee más de un nombre criollo. Esto se explica porque para la nomenclatura de los serranos el sustrato es un factor determinante. Por ello, si dos ejemplares crecen en el mismo sustrato se denominan de igual modo, aún cuando los campesinos reconozcan grandes diferencias morfológicas y los conciban como organismos o entidades diferentes. Igualmente, ejemplares que son idénticos, si están en sustratos distintos la mayoría de las veces llevan nombres distintos. Por ejemplo, por el nombre "florcita de espinillo" se denomina a un pequeño liquen como Parmotrema reticulatum y a un llamativo hongo como Inonotus rickii, pero a su vez a otro ejemplar de I. rickii se lo denominó "florcita de molle" cuando estaba creciendo sobre una rama de 'molle'. La importancia del sustrato para la nomenclatura de los hongos se percibe además en que de los 26 micónimos registrados tan sólo 5 ("hongo blanco", "hongo de comer", "hongo del diablo", "hongo veneno" y "polvillo del diablo") no hacen referencia al sustrato; el resto de los nombres (21) refieren al sustrato desde el que emerge el cuerpo fructífero.

\section{Las partes de los "hongos"}

Se podría proponer que la causa de las respuestas negativas ante la inquisitoria directa acerca de los nombres de las partes o estructuras de los hongos, tiene que ver con la manera de los campesinos de entender y percibir a estos fenómenos de un modo más bien holístico o integrador. Esta idea se sostiene en una frase que muchos repitieron casi textualmente: el hongo es uno, no tiene partes. La idea de la indivisibilidad de los hongos y este modo particular de percibirlos pareciera desaparecer a los fines prácticos o en la vida diaria cuando surge la necesidad de nombrar determinadas estructuras. En estos casos, la solución consiste en aplicarle un nombre que describe morfológicamente a la parte nombrada, haciendo uso de analogías con otros elementos más cotidianos y pertenecientes a otros ámbitos, como por ejemplo palito, platito, pielcita o cascarita. En definitiva, si bien los yuyeros 
perciben y reconocen distintas estructuras o partes en los hongos, este proceso sería en un principio inconsciente y entonces -hasta tanto no necesitan especificar a qué parte se refieren y aplicar términos precisos- prevalece la concepción sobre la unicidad e indivisibilidad de cada entidad.

\section{Las categorías vernáculas de los hongos}

A partir del análisis lingüístico de los nombres vernáculos, se pueden distinguir tres grupos o categorías que no se excluyen mutuamente y que llevan las siguientes etiquetas nomenclaturales: "hongo", "cascarita" y "florcita". Las especies que cuentan con alguno de estos términos formando parte del compuesto en al menos uno de sus nombres vernáculos, son clasificadas en la categoría homónima.

La categoría "hongo" engloba a un grupo de organismos independiente, que es definida por los campesinos a través de una serie de atributos ecológicos y morfológicos. Así, de acuerdo a las características descriptas por los campesinos, el "hongo" prototípico sería aquel organismo que emerge del suelo y presenta pie y sombrero: el típico 'hongo de sombrero'. Sin embargo, se observa que no todos esos atributos tienen el mismo peso, ya que por ejemplo si un organismo tiene como sustrato una roca no es considerado "hongo" (v. g. Usnea angulata); asimismo, todo organismo que cuenta con himenóforo y/o píleo y estípite, y crece sobre madera o tierra es considerado "hongo", aunque en algunos casos si no posee himenóforo y/o píleo y estípite pero crece sobre la tierra y se diferencia visiblemente (según la visión de los yuyeros) de plantas y yuyos (v. g. Calvatia cyathiformis), puede ser considerado igualmente un "hongo". Se puede afirmar entonces, que diferencias marcadas con vegetales son también un atributo importante que define a un organismo como "hongo" ya que, al menos para casos como el de los "polvillo del diablo", resulta determinante.

Por otra parte, ninguno de los líquenes recolectados (Canomaculina pilosa, Lepraria sp., Parmotrema praesorediosum, Parmotrema reticulatum, Punctelia microsticta, Ramalina celastri, Usnea amblyoclada, Usnea angulata) es considerado "hongo" por los campesinos. En algunos casos se debe a que están sobre rocas, y en general porque ninguno cuenta con himenóforo lamelar o poroide como el de los Basidiomycota estudiados u otra de las características propias de los "hongos". Tampoco son consideradas "hongo" las especies Byssomerulius corium, Truncospora sp. y Parasola plicatilis. Byssomerulius corium tiene una fructificación resupinada a efuso-refleja, y no cuenta con ninguno de los atributos morfológicos mencionados para los "hongos", de modo que queda claro por qué no es considerada dentro de esa categoría, pero para las especies restantes vale hacer ciertas aclaraciones para comprenderlo. En el caso de Truncospora sp. se la consideró una "cascarita" de palo y fue colocada por los entrevistados fuera de la categoría "hongo", aún cuando posee algunas de las características típicas (es xilófago, tiene un píleo evidente); muy probablemente haya pasado desapercibida debido al pequeño tamaño de los ejemplares recolectados y observados in situ. Mientras que por el lado de Parasola plicatilis, que es un típico 'hongo de sombrero' terrestre y cuenta por lo tanto con todos los atributos necesarios para ser concebido como un "hongo" (Fig. 2 F), sucedió que la única persona que lo pudo observar in situ no lo reconoció y alegó no haberlo visto nunca. Luego, otros entrevistados que tuvieron oportunidad de verlo, pero ya herborizado, tampoco lo reconocieron y sostuvieron en su mayoría que era sólo un "pastito". Si bien los testimonios fueron contundentes, es probable que si más entrevistados lo hubieran podido observar in situ otros hubieran sido los resultados encontrados, ya que al ser herborizado el basidioma se seca prácticamente por completo y pierde el volumen casi en su totalidad, por lo cual su reconocimiento se torna muy dificultoso.

Las categorías "florcita" y "cascarita" son conceptos sin duda complejos, que requieren de un mayor tratamiento y análisis en el futuro. Sin embargo, se pudieron definir en forma provisoria en base a las descripciones y denominaciones de los campesinos, $\mathrm{y}$, al igual que con las demás categorías, fue posible determinar una serie de atributos propios para cada una. Así, las especies incluidas en estos dos agrupamientos pueden tener como sustrato únicamente a rocas o vegetales (nunca tierra), pero las "florcitas" son de colores llamativos y vistosos y/o por su forma o tamaño sobresalen y se diferencian visiblemente de la superficie del sustrato, mientras que las "cascaritas" son especies de colores y formas miméticos o de menor contraste con los del sustrato. De esta 


\section{Flamini et al. - Nombres y clasificaciones de los hongos de La Paz, Córdoba}

forma, los líquenes fruticulosos son incluidos en la categoría "florcita" y los hongos no-liquenizados del tipo "florcita" son siempre de mayor tamaño y volumen que aquellos considerados "cascaritas". Estas generalidades se adecúan bastante bien a los resultados obtenidos, pero es muy importante remarcar que, aún cuando los atributos que definen a cada categoría son compartidos por todos los campesinos, siempre existe un gran componente de subjetividad, ya que al momento de discernir si un ejemplar pertenece a una u otra categoría, todo queda supeditado a la percepción que posea cada persona sobre las características del material evaluado. Por este motivo, en ocasiones un mismo ejemplar pueda ser clasificado en dos categorías distintas.

De todas maneras, como las categorías no son excluyentes, hay especies que pueden formar parte de más de una al mismo tiempo dependiendo de las características propias de cada ejemplar. En este sentido, sólo los líquenes Lepraria sp. y Ramalina celastri fueron catalogados por los campesinos exclusivamente como "florcita", y las especies Truncospora sp., Byssomerulius corium, Punctelia microsticta y Parmotrema praesorediosum fueron incluidas solamente en la categoría "cascarita". En cambio, los hongos Trametes hirsuta, Pycnoporus sanguineus, Funalia gallica, Phellinus rimosus, Inonotus rickii y Ganoderma resinaceum fueron nombrados tanto "florcitas" como "hongos" (específicamente son considerados "hongo de palo"), las especies Schizophyllum commune y Gloeophyllum striatum fueron llamadas bajo las categorías "cascarita" y "hongo" ("hongo de palo"), y los líquenes Parmotrema reticulatum y Canomaculina pilosa fueron denominados "cascarita" y "florcita".

Una particularidad respecto de los nombres "florcitas" y "cascaritas", que deviene importante en el estudio de la nomenclatura asociada a la flora del entorno, es que el uso del diminutivo en dichos términos es una marca lingüística que los diferencia de las flores del palo y la cáscara del palo, esto es, las flores y la corteza de los vegetales, y se los identifica como entidades u organismos diferentes al palo sobre el que crecen, que lo usan como sustrato pero no forman parte de él. Teniendo esto en cuenta, y como se mencionó más arriba, ni las "florcitas" ni las "cascaritas" son concebidas como plantas o yuyos, pero tampoco podrían incluirse en su conjunto como "hongos" ya que algunas no son consideradas como tales. Serían, pues, dos categorías que están constituidas por algunas especies que son consideradas "hongo", "hongos de palo" específicamente, pero también por especies que no son otra cosa más que "florcitas" o "cascaritas" (esto ocurre principalmente con los líquenes), y que están íntimamente relacionadas entre sí, en tanto que se definen por características opuestas, contrastantes. Que los yuyeros separen a los líquenes del grupo de los "hongos" no resulta tan llamativo si se tiene en cuenta que estos organismos están conformados por una simbiosis entre un micobionte y un fotobionte, y que por ello, a diferencia del resto de los hongos, realizan fotosíntesis y poseen formas y estructuras muy particulares.

Por su parte, no se encontró una postura clara respecto a las "barba de piedra" y su ubicación en alguna de las categorías recién definidas. Las "barba de piedra" no son consideradas "hongos" porque tienen como sustrato a las rocas, y aunque los criollos serranos consideran que tienen ciertas similitudes morfológicas con los vegetales tampoco son consideradas de esa manera por una gran mayoría de los campesinos entrevistados (10), porque para ellos los vegetales sólo crecen en la tierra. Por el hecho de estar sobre rocas y poseer un talo de tipo fruticuloso se podría suponer que forman parte de la categoría "florcita", pero ningún informante la llamó de ese modo o la consideró explícitamente así. Nuevamente queda pendiente para el futuro intentar corroborar o refutar esta hipótesis sobre la ubicación de las "barba de piedra" en la taxonomía vernácula.

Las categorías "hongos de tierra", "hongos de palo", "hongos de comer" y "hongos de palo verdaderos" presentan un cierto grado de ordenamiento jerárquico. La primera dicotomía de la agrupación "hongos" es la que se plantea según el sustrato: los "hongos de tierra" y los "hongos de palo". Entre los "hongos de palo" también existe una subdivisión relacionada a la utilidad y a ciertos atributos morfológicos de los individuos: los "hongos de comer" y los "hongos de palo verdaderos". Los primeros sólo incluyen dos hongos, o tres de acuerdo a algunos informantes: "hongo de pino", "hongo de coco" y/u "hongo de molle". Al igual que los demás "hongos de palo", sus nombres provienen de la asociación con el árbol 
sobre el que crecen, esto es, con el 'pino honguero' (Pinus halepensis) en el caso del "hongo de pino", con el 'coco' (Zanthoxylum coco) en el del "hongo de coco", o con el 'molle' (L. molleoides) en el caso del "hongo de molle". Así, podemos observar que, tal como encuentraron diversos autores en otras sociedades (v. g. Shepard \& Arora, 1994; Lampman, 2004; Suárez, 2014), existe una clara distinción entre los hongos terrestres y los hongos en estante, pero que en este caso no se presenta como una dicotomía muy clara entre dos grupos opuestos, sino que simplemente se aprecia en la agrupación de los hongos en estante en la categoría "hongos de palo verdadero" en oposición a los comestibles.
En base a todo lo antedicho se propone un primer esquema del sistema de clasificación local de los hongos estudiados, que, aunque provisorio, puede servir de base para futuras investigaciones que se dediquen a continuar indagando sobre la temática entre los serranos de Traslasierra y otros campesinos de la provincia y la región (Fig. 3).

El concepto vernáculo de hongo, las formas de definirlo y las especies incluidas en esta categoría, presenta diferencias con aquellos de la ciencia académica. Esto no es raro: qué es un "hongo" y las clasificaciones etnomicológicas suelen no coincidir, al menos no plenamente, con las de la ciencia académica (v. g. Mapes et al., 1981; Ellen 2008, Suárez, 2014). Esto se corresponde con el hecho

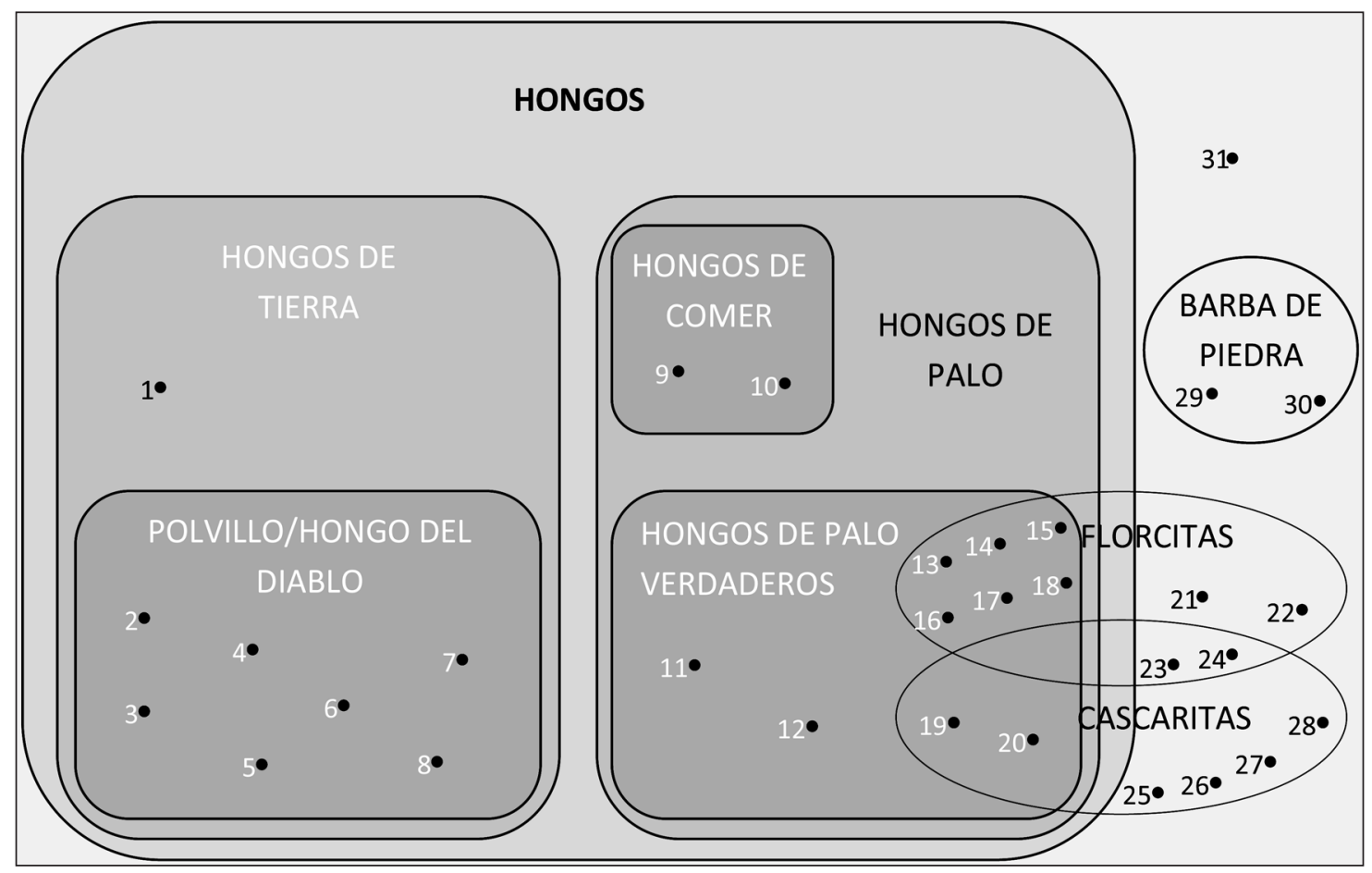

Fig. 3. Esquema del sistema de clasificación de los yuyeros de Traslasierra. Referencias: 1= Agaricus spp.; $2=$ Bovista cunninghamii; $3=$ Calvatia cyathiformis; $4=$ Calvatia fragilis; $5=$ Disciseda candida; $6=$ Mycenastrum corium; $7=$ Myriostoma coliforme; $8=$ Scleroderma bovista; $9=$ Phlebopus bruchii; $10=$ Suillus granulatus; 11= Fuscoporia wahlbergii; 12= Gymnopilus chrysopellus; 13= Funalia gallica; 14= Ganoderma resinaceum; 15= Inonotus rickii; 16= Phellinus rimosus; 17= Pycnoporus sanguineus; 18= Trametes hirsuta; 19= Gloeophyllum striatum; 20= Schizophyllum commune; 21= Lepraria sp.; 22= Ramalina celastri; 23= Canomaculina pilosa; 24 $=$ Parmotrema reticulatum; 25= Byssomerulius corium; 26= Parmotrema praesorediosum; 27= Punctelia microsticta; 28= Truncospora sp.; 29= Usnea amblyoclada; 30= Usnea angulata; $31=$ Parasola plicatilis. 


\section{Flamini et al. - Nombres y clasificaciones de los hongos de La Paz, Córdoba}

de que es frecuente que las taxonomías vernáculas no sean jerárquicas como la Linneana, sino más bien un conjunto de categorías yuxtapuestas (Johnson, 1999; Ellen, 2000, 2008; Scarpa, 2012a); los resultados encontrados entre los campesinos de Traslasierra indican que, a diferencia de lo que propone Berlin (1992) sobre la organización jerárquica de los sistemas clasificatorios tradicionales, sus concepciones al respecto no seguirían este patrón (Fig. 3). De todas maneras, es preciso destacar que los yuyeros serranos de Córdoba consideran que existe un grupo de organismos independiente de plantas y animales, que engloba a la mayoría de los macrohongos recolectados durante las campañas de campo. Este conocimiento fue obtenido y transmitido por generaciones pasadas, fruto del contacto e interés por los elementos naturales más allá de su utilidad o no, y muestra la profundidad y validez de saberes que poseen los campesinos, situación que toma mayor relevancia si se considera que la "ciencia occidental" recién aceptó la separación de los hongos como un filo independiente de los vegetales entre los años 1980 y 1990.

\section{ConClusiones}

Los datos registrados y los estudios realizados han permitido conocer parte de la riqueza de conocimientos de los serranos sobre los hongos de su entorno. Por un lado, la atención y el análisis pormenorizado de la nomenclatura vernácula asociada a los hongos, muestran evidencias concretas del amplio conocimiento que tienen los serranos sobre los hongos de su entorno: los campesinos cuentan con un léxico específico relativo a la morfología y nomenclatura de las partes de los hongos estudiados, aplican términos concretos para referirse a distintas partes o características de los hongos y en sus nombres se explicitan ciertas particularidades de cada especie, como los sustratos sobre los que crecen, colores, toxicidad, entre otros.

Por otro lado, los resultados generales obtenidos demuestran que conocen pormenores del ciclo de vida, de la ontogenia, del hábitat, de la época del año en que crecen, entre otros detalles. Todos los criterios de los yuyeros para el reconocimiento de una u otra especie, o para su clasificación en distintas categorías vernáculas ("hongos", "cascaritas", "florcitas"), manifiestan su manera peculiar de observar, concebir y ordenar los elementos que conforman su entorno, y son una muestra clara del grado de detalle de sus saberes micológicos (morfología, sustratos, asociaciones con vegetales). A su vez, los serranos mantienen un vínculo estrecho aún con aquellas especies que no se revelan directamente como significativas a nivel utilitario y/o simbólico: las observan, las conocen en detalle y las consideran parte sustancial de los elementos que conforman su hábitat.

El análisis holístico e interpretativo de los datos registrados nos lleva a concluir que los campesinos de Traslasierra no son micófilos al grado de otras culturas o grupos humanos, como pueden ser los rusos o ciertas culturas de las tierras altas mesoamericanas (Fericgla, 1994; Mapes et al., 2002), pero tampoco se puede decir que sean micófobos, ya que no tienen sentimientos de rechazo, les rehúyen o muestran resquemores, aún con hongos que parecieran tener para ellos ciertas connotaciones negativas, como puede ser "hongo veneno" y "polvillo del diablo". Algo similar, es decir, culturas que conocen en profundidad los hongos de su entorno pero que no son micófilas ni micófobas, se encuentra en diversas sociedades por todo el mundo (v. g. Mapes et al., 1981; RuánSoto et al., 2004; Ellen, 2008; Suárez, 2014). En realidad, las distinciones entre pueblos micófilos y micófobos fue propuesta por Wasson \& Wasson (1957), pero ya hace mucho tiempo son categorías harto cuestionadas, o al menos la distinción tajante ha mostrado ser dos extremos de lo que en realidad sería más bien un continuo (Arora \& Shepard, 2008; Ruán-Soto et al., 2013). De esta forma, los yuyeros serranos son un ejemplo más que contribuye a desmitificar la necesidad de clasificar a las culturas en alguno de los dos polos.

Para terminar, se destaca que los objetivos planteados para esta investigación fueron alcanzados. Se identificaron 31 especies fúngicas conocidas por los campesinos de Traslasierra, sus nombres vernáculos y las motivaciones y significados de los mismos fueron registrados y estudiados en detalle. Se pudo indagar y obtener datos sobre las creencias y sentimientos de la gente acerca de los distintos hongos. El análisis integrado de los nombres vernáculos y otros resultados obtenidos, permitieron incluso proponer 
un esquema etnoclasificatorio provisorio de los hongos estudiados. Se espera proseguir indagando en el futuro sobre la etnomicología de los campesinos de Traslasierra, con el fin de ampliar el número e identidad de especies fúngicas estudiadas, corroborar o refutar lo planteado hasta aquí, y también para comprender aquellos resultados que no quedaron del todo claros, como ser las motivaciones detrás de ciertos nombres vernáculos (v. g. "hongo del diablo", "polvillo del diablo"). De esta forma, los resultados de esta investigación, si bien novedosos, se consideran tan sólo el inicio de una investigación que a futuro puede brindar un panorama general y más completo de los saberes micológicos de los campesinos de Traslasierra.

\section{Agradecimientos}

A todos los entrevistados que entre mates y charlas informales compartieron las historias y conocimientos que permitieron este trabajo. A la familia Rintisch por todo el apoyo durante los viajes. A Paola Cúneo y Juan Manuel Rodríguez por la colaboración desinteresada con los análisis lingüísticos y la identificación de líquenes respectivamente.

\section{Bibliografía}

ACOSTA, C. A. 2009. Variedades de vegetales y de hongos existentes en la República Argentina y poseedoras de principios Psicoactivos. Tesis de maestría, Universidad Nacional de Córdoba.

ALCARAZ VARÓ, E. \& M. A. MARTÍNEZ LINARES. 1997. Diccionario de Lingüística moderna. Ariel, Barcelona.

ARAGÓN, R. \& J. M. MORALES. 2003. Species composition and invasion in NW Argentinian secondary forests: Effects of land use history, environment and landscape. J. Veget. Sci. 14: 195204.

ARENAS, P. 2003. Etnografia y alimentación entre los Toba-Nachilamolettek y Wichi-Lhuku'tas del Chaco Central (Argentina). Ed. del autor, Buenos Aires.

ARENAS, P. \& G. J. MARTÍNEZ. 2012. Estudio etnobotánico en regiones áridas y semiáridas de Argentina y zonas limítrofes. Experiencias y reflexiones metodológicas de un grupo de investigación. En: ARENAS, P. (ed.), Etnobotánica en zonas áridas y semiáridas del Cono Sur de
Sudamérica, pp. 11-43. CEFYBO-CONICET, Buenos Aires.

ARIAS TOLEDO, B. 2006. Aspectos cuantitativos, cualitativos y simbólicos de la medicina tradicional de los pobladores criollos de Cerro Colorado (Córdoba, Argentina). PINACO, Programa investig. antropol. cogn. 6: 105-115.

ARIAS TOLEDO, B. 2009. Diversidad de usos, prácticas de recolección y diferencias según género y edad en el uso de plantas medicinales en Córdoba, Argentina. Bol. Latinoam. Caribe Plant. Med. Aromat. 8: 389401.

ARIAS TOLEDO, B., S. COLANTONIO \& L. GALETTO. 2007. Knowledge and use of edible and medicinal plants in two populations from the Chaco forest, Córdoba province, Argentina. J. Ethnobiol. 27: 218-232.

ARORA, D. \& G. H. SHEPARD. 2008. Mushrooms and Economic Botany. Econ. Bot. 62: 207-212.

BERNARD, H. R. 2000. Social Research Methods: Qualitative and Quantitative Approaches. SAGE Publications, California.

BERLIN, B. 1992. Ethnobiological Classification: Principles of Categorization of Plants and Animals in Traditional Societies. Princeton University Press, New Jersey.

BOA, E. 2004. Wild edible fungi: a global overview of their use and importance to people. Non-Wood Forest Products 17. FAO, Roma.

BOOIJ, G. 2005. Compounding and derivation: evidence for Construction Morphology. In: DRESSLER, W. U., D. KASTOVSKY, O. E. PFEIFFER \& F. RAINER (eds.), Morphology and its demarcations, pp. 109-32. John Benjamins, Amsterdam / Philadelphia.

BUGUÑA, P. \& C. I. COMETTA (coords.). 2010. Diagnóstico preliminar y formulación de proyectos. Municipalidad de La Paz, Valle de Traslasierra. Provincia de Córdoba, Argentina. Instituto del Ambiente Liliana Rainis. FAUDI-UNC. Disponible en: http://es.scribd.com/doc/45058814/DiagnosticoLa-Paz [Acceso: 10 diciembre 2013].

BUSTOS GISBERT, E. 1986. La composición nominal en español. Ediciones Universidad de Salamanca, Salamanca.

CABRERA, A. L. 1971. Regiones fitogeográficas de la República Argentina. Bol. Soc. Argent. Bot. 14: 1-42.

CARDONA, G. R. 1994. Los lenguajes del saber. Gedisa, Barcelona.

COIRINI, R. \& C. W. ROBLEDO. 1999. Elementos de Diagnóstico Rural Rápido. En: CASERMERIO, J. \& E. SPAHN (eds.), Sistemas agroforestales para pequeños productores de zonas húmedas, pp. 158163. Universidad Nacional de Entre Ríos, Entre Ríos. 


\section{Flamini et al. - Nombres y clasificaciones de los hongos de La Paz, Córdoba}

DESCHAMPS, J. R. 2002. Hongos silvestres comestibles del Mercosur con valor gastronómico. Documento de Trabajo $N^{\circ} 86$, Universidad de Belgrano. Disponible en: http://www.ub.edu.ar/investigaciones/dt nuevos/86 deschamps.pdf [Acceso: 20 julio 2013].

DOMÍNGUEZ, L. S. \& M. L. HERNÁNDEZ CAFFOT. 2011. Hongos venenosos de Córdoba. Infografía publicada por el Ministerio de ciencia y tecnología del gobierno de la Provincia de Córdoba.

DOMÍNGUEZ DÍAZ, E. 2010. Flora de interés etnobotánico usada por los pueblos originarios: Aónikenk, Selk'nam, Kawésqar, Yagan y Haush en la Patagonia Austral. Dominguezia 26: 19-29.

DURANTI, A. 2000. Antropología lingüística. Cambridge University Press, Madrid.

ELLEN, R. 2000. The cultural relations of classification. An analysis of Nuaulu animal categories from Central Seram. Cambridge University Press, Cambridge.

ELLEN, R. 2008. Ethnomycology among the Nuaulu of the Moluccas: Putting Berlin's "General Principles" of Ethnobiological Classification to the Test. Econ. Bot. 62: 483-496.

FAJARDO, J., A. VERDE, A. VALDÉS, D. RIVERA \& C OBÓN. 2010. Etnomicología en Castilla-La Mancha (España). Bol. Soc. Micol. Madrid 34: 341360.

FERICGLA, J. M. 1994. El hongo y la génesis de las culturas. Duendes y gnomos: Ámbitos culturales forjados por el consumo de la seta enteógena Amanita muscaria. Los Libros de la Liebre de Marzo, Barcelona.

FERNÁNDEZ, M. V., C. BARROETAVEÑA, V. BASSANI \& F. RÍOS. 2012. Rentabilidad del aprovechamiento del hongo comestible Suillus luteus para productores forestales y para familias rurales de la zona cordillerana de la provincia del Chubut, Argentina. Bosque 33: 43-52.

FILIPOV, A. \& P. ARENAS. 2008. Los vegetales en el ciclo reproductivo de la mujer pilagá. Supl. Antropol. 43: 211-236.

FOWLER, C. S. 1979. Etnoecología. En: HARDESTY, D. L. (ed.) Antropología ecológica, pp. 215-238. Bellaterra, Barcelona.

FURLAN, V., C. TORRES \& L. GALETTO. 2011. Conocimiento y utilización de plantas medicinales por pobladores rurales del bosque chaqueño serrano de Córdoba (Argentina). Bonplandia 20: 179-201.

GONZÁLEZ MONTEAGUDO, J. 2000. El paradigma interpretativo en la investigación social y educativa: nuevas respuestas para viejos interrogantes. Cuestiones pedagógicas: Revista Ciencias Educ. 15: 227-246.

GRAJALES VÁSQUEZ, A. G., R. K. V. ALVARADO, D. Y. SÁNCHEZ MOLINA, I. Y. R. MÉRIDA,
J. L. S. RAMÍREZ \& F. R. SOTO. 2008. Estudio etnomicológico en San Antonio Linda Vista, municipio de La Independencia, Chiapas. Lacandonia 2: 5-16.

GUBER, R. 2001. La Etnografía: método, campo y reflexibidad. Norma, Bogotá.

HERNÁNDEZ, M. P., S. M. CIVITELLA \& V. G. ROSATO. 2010. Uso medicinal popular de plantas y líquenes de la Isla Paulino, Provincia de Buenos Aires, Argentina. Bol. Latinoam. Caribe Plant. Med. Aromat. 9: 258-268.

HUNN, E. 1982. The Utilitarian Factor in Folk Biological Classification. Am. Anthropol. 84:830-847.

ISE (INTERNATIONAL SOCIETY OF ETHNOBIOLOGY). 2006. Código de ética de la sociedad internacional de etnobiología. Disponible en: http://ethnobiology.net/docs/Codigo_Etica ISE_2006_w-additions_espanol_Feb2011.pdf [Acceso: 30 julio 2013].

JIMÉNEZ GONZÁLEZ, M. 2008. Uso de los macromicetes de Molango de Escamilla, Hidalgo, México. Tesis de grado, Universidad Autónoma del Estado de Hidalgo.

JOHNSON, L. M. 1999. Gitksan plant classification and nomenclature. J. Ethnobiol. 19: 179-218.

KELLER, H. A. 2000. Lentinus velutinus (LentinaceaePoriales), un indicador de maderas para pipas entre los guaraníes de Misiones. Bonplandia 10: 189-191.

KELLER, H. A. 2008. Relación entre las dimensiones del cuerpo fructífero y el pseudoesclerocio de Lentinus velutinus (Lentinaceae-Poriales), validación de una hipótesis sugerida por los guaraníes de Misiones, Argentina. Bonplandia 17: 29-34.

KELLER, H. A. 2010. Plantas colorantes utilizadas por los guaraníes de Misiones, Argentina. Bonplandia 19: 11-25.

LADIO, A. H. 2001. The maintenance of wild edible plant gathering in a Mapuche community of Patagonia. Econ. Bot. 55: 243-254.

LAGROTTERIA, M. \& M. AFFOLTER. 1999. Sustainable production and harvest of medicinal and aromatic herbs in the Sierras de Córdoba Region. Argentina. In: NAZAREA, V. D. (ed.), Ethnoecology: Situated Knowledge/Located lives, pp. 175-189. The University of Arizona Press, Tucson.

LAMPMAN, A. M. 2004. Tzeltal Ethnomycology: Naming, Classification and Use of Mushrooms in the Highlands of Chiapas, Mexico. Ph.D. dissertation, University of Georgia.

LÉVI-STRAUSS, C. 1964. El pensamiento salvaje. Fondo de Cultura Económica, México.

LUTI, R., M. A. BERTRAND DE SOLIS, F. M. GALERA, N. MÜLLER, M. BERZAL, M. NORES, M. A. HERRERA \& J. C. BARRERA. 1979. 
Vegetación. En: VÁZQUEZ, J. B., R. MIATELLO \& M. E. ROQUÉ (eds.), Geografía Física de la Provincia de Córdoba, pp. 297-368. Boldt, Córdoba.

MADALENO, I. M. \& M. C. MONTERO. 2012. El cultivo urbano de plantas medicinales, su comercialización y usos fitoterapéuticos en la ciudad de Río Cuarto, provincia de Córdoba, Argentina. Cuadernos Geográficos 50: 63-85.

MAPES, C., G. GUZMÁN \& J. CABALLERO. 1981. Etnomicología purépecha. El conocimiento y uso de los hongos en la cuenca del lago de Pátzcuaro, Michoacán. Dirección General de Culturas Populares. Secretaría de Educación Pública/ Instituto de Biología. UNAM/Sociedad Mexicana de Micología, México.

MAPES, C., F. P. BANDEIRA, J. CABALLERO \& A. GOES-NETO. 2002. Mycophobic or Mycophilic? a comparative Etnomycological study between Amazonia and Mesoamerica. In: STEPP, J. R., F. S. WYNDHAM \& R. K. ZARGER (eds.), Ethnobiology and Biocultural Diversity: Proceedings of the Seventh International Congress of Ethnobiology: 2327 october, 2000, pp 180-188. University of Georgia Press, Athens.

MARTIN, G. J. 1995. Ethnobotany: a methods manual. Chapman \& Hall, London.

MARTÍNEZ, G. J. 2005. Recolección y Comercialización de Plantas Medicinales en el Departamento Santa María, Provincia de Córdoba, Argentina. Acta Farm. Bonaerense 24: 575-584.

MARTÍNEZ, G. J. 2007. La farmacopea natural en la salud materno-infantil de los Tobas del Río Bermejito. Kurtziana 33: 39-63.

MARTÍNEZ, G. J. 2008. Farmacopea natural y tratamiento de afecciones de la piel en la medicina tradicional de los campesinos de las sierras de Córdoba (República Argentina). Dominguezia 24: 27-46.

MARTÍNEZ, G. J. 2010. Las plantas en la medicina tradicional de las sierras de Córdoba. Un recorrido por la cultura campesina de Paravachasca $y$ Calamuchita. Ediciones del Copista, Córdoba.

MARTÍNEZ, G. J. \& P. CÚNEO. 2009. Las denominaciones vernáculas y el conocimiento toba del entorno vegetal. RDTP 64: 149-168.

MARTÍNEZ, G. J. \& A. M. PLANCHUELO. 2003. La medicina tradicional de los criollos campesinos de Paravachasca y Calamuchita, Córdoba (Argentina). Scr. Ethnol. 25: 83-116.

MARTÍNEZ CROVETTO, R. 1968. Nombres de plantas y su utilidad, según los indios onas de Tierra del Fuego. Etnobiológica 4: 1-20.

MELLO AMOROZO, M. C. \& R. B. VIERTLER. 2008. A abordagem qualitativa na coleta e análise de dados etnobotânicos. En: ALBUQUERQUE, U. P., R. F. P.
LUCENA \& L. V. F. C. CUNHA (orgs.), Métodos e técnicas na pesquisa etnobotânica, pp. 73-91. $2^{\circ}$ ed. Comunigraf Editora, Recife.

MESSINEO, C. 2009. Modos de clasificación nominal en el dominio de la flora y de la fauna en maká (familia mataco-mataguaya). UniverSOS 6: 119-138.

MESSINEO, C. \& P. CÚNEO. 2007. Derivación, composición y clasificación nominal. Recursos lingüísticos comunes a la nomenclatura de plantas $\mathrm{y}$ animales en dos lenguas indígenas del Chaco: toba y maká. Proceedings of the III Conference on Indigenous Languages of Latin America, University of Texas at Austin, Austin.

MESSINEO, C. \& T. TACCONI. 2010. Recursos de formación del léxico en maká (mataguayo): zoonimia y fitonimia. En: MESSINEO, C., G. F. SCARPA \& F. TOLA (comp.), Léxico y categorización etnobiológica en grupos indígenas del Gran Chaco, pp. 83-116. Instituto de Lingüística, Facultad de Ciencias Humanas, Universidad Nacional de La Pampa, Santa Rosa.

MORENO FUENTES, A., E. AGUIRRE-ACOSTA \& L. PÉREZ-RAMÍREZ. 2004. Conocimiento tradicional y científico de los hongos en el estado de Chihuahua, México. Etnobiología 4: 89-105.

NIVEIRO, N., O. F. POPOFF \& E. O. ALBERTÓ. 2009. Hongos comestibles silvestres: especies exóticas de Suillus (Boletales, Basidiomycota) y Lactarius (Russulales, Basidiomycota) asociadas a cultivos de Pinus elliottii del Nordeste argentino. Bonplandia 18: $65-71$.

OCHOA, J. J., A. H. LADIO \& M. LOZADA. 2010. Uso de recursos herbolarios entre mapuches y criollos de la comunidad campesina de Arroyo Las Minas (Río Negro, Patagonia Argentina). Bol. Latinoam. Caribe Plant. Med. Aromat. 9: 269-276.

ROBLEDO, G. \& C. URCELAY. 2009. Hongos de la madera en árboles nativos del centro de Argentina. Editorial Universitaria, Universidad Nacional de Córdoba.

RUAN SOTO, F., J. CABALLERO, C. MARTORELL, J. CIFUENTES, A. R. GONZÁLEZ-ESQUINCA \& R. GARIBAY-ORIJEL. 2013. Evaluation of the degree of mycophilia-mycophobia among highland and lowland inhabitants from Chiapas, Mexico. $J$ Ethnobiol Ethnomedicine 9: 36-50.

RUÁN SOTO, F., R. GARIBAY-ORIJEL \& J. CIFUENTES. 2004. Conocimiento micológico tradicional en la planicie costera del Golfo de México. Revista Mexic. Micol. 19: 57-70.

RUÁN SOTO, F., R. MARIACA MÉNDEZ, J. CIFUENTES, F. LIMÓN AGUIRRE, L. PÉREZ RAMÍREZ \& S. SIERRA GALVÁN. 2007. Nomenclatura, clasificación y percepciones locales acerca de los hongos en dos comunidades de la selva 


\section{Flamini et al. - Nombres y clasificaciones de los hongos de La Paz, Córdoba}

lacandona, Chiapas, México. Etnobiología 5: 1-20.

SÁNCHEZ MÉNDEZ, J. 2009. La formación de palabras por composición desde un punto de vista histórico. Revista Filol. Esp. 89: 103-128.

SCARPA, G. F. 2009. Etnobotánica médica de los indígenas chorote y su comparación con la de los criollos del chaco semiárido (Argentina). Darwiniana 47: 92-107.

SCARPA, G. F. 2012a. "Palos, yuyos, pencas, bejucos y pastos": los nombres de las plantas y su clasificación etnobotánica por los criollos del chaco semiárido norte (NE Salta - W Formosa, Argentina). En: ARENAS, P. (ed.), Etnobotánica en zonas áridas y semiáridas del Cono Sur de Sudamérica, pp. 117144. CEFYBO-CONICET, Buenos Aires.

SCARPA, G. F. 2012b. Las plantas en la vida de los criollos del oeste formoseño. Medicina, ganadería, alimentación y viviendas tradicionales. Asociación Civil Rumbo Sur, Buenos Aires.

SCARPA, G. F. 2013. Medicina indigena Chorote. Continuidad y transformaciones históricas $y$ culturales. Editorial Académica Española, Saarbrücken.

SCHULTES, R. E. \& A. HOFMANN. 2000. Plantas de los dioses. Orígenes del uso de los alucinógenos. $2^{\circ}$ ed. Fondo de Cultura Económica, México.

SHEPARD, G. H. \& D. ARORA. 1994. The Forgotten Kingdom: Mushrooms and Ethnobiology. American Anthropological Association Meetings, Atlanta.

SIlVA, V. A., U. P. ALBUQUERQUE \& V. T. NASCIMENTO. 2008. Técnicas para análise de dados etnobotânicos. En: ALBUQUERQUE, U. P., R. F. P. LUCENA \& L. V. F. C. CUNHA (orgs.), Métodos e técnicas na pesquisa etnobotânica, pp. 127-143. $2^{\circ}$ ed. Comunigraf Editora, Recife.

SUÁREZ, M. E. 2010. Fitonimia wichí de especies arbóreas y arbustivas del Chaco Semiárido salteño. En: MESSINEO, C., G. F. SCARPA \& F. TOLA (comp.), Léxico y categorización etnobiológica en grupos indígenas del Gran Chaco, pp. 199224. Instituto de Lingüística, Facultad de Ciencias Humanas, Universidad Nacional de La Pampa, Santa Rosa.

SUÁREZ, M. E. 2011. Fitonimia wichí de plantas herbáceas y bejucos. Bonplandia 20: 185-202.

SUÁREZ, M. E. 2014. Etnobotánica wichí del bosque xerófito en el Chaco Semiárido salteño. Autores de Argentina, Don Torcuato.

SUÁREZ, M. E. \& P. ARENAS. 2012. Plantas y hongos tintóreos de los wichís del Gran Chaco. Bol. Soc. Argent. Bot. 47: 275-283.
SUÁREZ, M. E. \& R. M. MONTANI. 2010. Vernacular knowledge of Bromeliaceae species among the Wichí people of the Gran Chaco, Argentina. J. Ethnobiol. 30: 265-288.

TAYLOR S. J. \& R. BOGDAN. 1987. Introducción a los Métodos Cualitativos de Investigación. Editorial Paidós, Buenos Aires.

TRILLO, C. 2010. Valoración del bosque y conocimiento de las plantas silvestres por parte de los pobladores de las Sierras de Guasapampa, Noroeste de la Provincia de Córdoba. Tesis doctoral, Universidad Nacional de Córdoba.

TRILLO, C. \& P. DEMAIO. 2007. Tintes naturales. Guía para el reconocimiento y uso de plantas tintóreas del Centro de Argentina. Editorial Sezo, Córdoba.

TRILlO, C., P. DEMAIO, S. COLANTONIO \& L. GALETTO. 2007. Conocimiento actual de plantas tintóreas por los pobladores del valle de Guasapampa, provincia de Córdoba. Kurtziana 33: 65-71.

VELASCO, J. M., A. MARTIN \& A. GONZÁLEZ. 2011. Los nombres comunes y vernáculos castellanos de las setas: Micoverna-I. Primera recopilación realizada a partir de literatura micológica e informantes. Bol. Micolog. FAMCAL 6: 155-216.

WAHYUNI, D. 2012. The Research Design Maze: Understanding Paradigms, Cases, Methods and Methodologies. JAMAR 10: 69-80.

WASSON, R. G., A. HOFFMAN, \& C. A. P. RUCK. 2008. The road to Eleusis: unveiling the secrets of the mysteries. North Atlantic Books, California.

WASSON, V. \& R. G. WASSON. 1957. Mushroom, Russia and History. Volume 1. Pantheon Books, New York.

YAMIN PASTERNAK, S. 2011. Ethnomycology: Fungi and Mushrooms in Cultural Entanglements. In: ANDERSON, E. N., D. M. PEARSALL, E. S. HUNN \& N. J. TURNER (eds.), Ethnobiology, pp. 213-230. Wiley-Blackwell, Hoboken.

ZAK, M. R., M. CABIDO \& J. G. HODGSON. 2004. Do subtropical seasonal forests in the Gran Chaco, Argentina, have a future? Biol. Conserv. 120: 589598.

ZENT, E. L., S. ZENT, \& T. ITURRIAGA. 2004. Knowledge and use of fungi by a mycophilic society of the Venezuelan Amazon. Econ. Bot. 58: 214-226.

Recibido el 6 de noviembre de 2014, aceptado el 13 de mayo de 2015. 
